\title{
$\angle S$ Research Square \\ Fruit juice mediated multicomponent reaction for the synthesis of substituted isoxazoles and their in vitro bio evaluation
}

Susheel Gulati Shelu ( $\sim$ sgbhuna@hau.ac.in )

Chaudhary Charan Singh Haryana Agricultural University

Rajvir Singh Rajvir

Chaudhary Charan Singh Haryana Agricultural University

\section{Suman Sangwan Suman}

Chaudhary Charan Singh Haryana Agricultural University

\section{Research Article}

Keywords: Isoxazole, Cocos nucifera L. juice, Solanum lycopersicum L. juice, Citrus limetta juice

Posted Date: April 9th, 2021

DOI: https://doi.org/10.21203/rs.3.rs-369459/v2

License: (1) (i) This work is licensed under a Creative Commons Attribution 4.0 International License.

Read Full License

Version of Record: A version of this preprint was published at Scientific Reports on December 1st, 2021. See the published version at https://doi.org/10.1038/s41598-021-03057-6. 


\section{Abstract}

A simple, efficient and eco-friendly procedure for the synthesis of isoxazoles derivatives (4a-4h) using one-pot three components reaction between substituted aldehydes (1a), methyl acetoacetate (2a) and hydroxylamine hydrochloride (3a) has been achieved in presence of Cocos nucifera L. juice, Solanum lycopersicum L. juice and Citrus limetta juice respectively. This protocol is natural acid catalysed multicomponent reaction for the synthesis of potentially bioactive isoxazole derivatives. The homogeneity of synthesized compounds was confirmed by melting point and thin layer chromatography. The synthesized compounds were characterized by using ${ }^{1} \mathrm{HNMR}, \mathrm{FTIR}$ and $\mathrm{CHN}$ spectral analysis and evaluated for in vitro herbicidal activity against Raphanus sativus L. (Radish seeds). The compounds (4a4h) were also screened for their fungicidal activity against Rhizoctonia solani and Colletotrichum gloeosporioides by poisoned food techniques. Antibacterial activity was also tested against Erwinia carotovora and Xanthomonas citri by inhibition zone method. From bio evaluation data, it was found that compound $\mathbf{4 b}$ was most active against Raphanus sativus L. (root) and Raphanus sativus L. (shoot) respectively. Compound $\mathbf{4 b}$ was also found most active against both the fungus viz. $R$. solani and $C$. gloeosporioides showing maximum percentage growth inhibition i.e. 90.00 against $R$. solani and 82.45 against $C$. gloeosporioides at $2000 \mu \mathrm{g} / \mathrm{mL}$ concentration. Compound $\mathbf{4 h}$ has shown maximum inhibition zone i.e. 3.00-9.60 mm against Erwinia carotovora at $2000 \mu \mathrm{g} / \mathrm{mL}$ concentration. Maximum Xanthomonas citri growth was also inhibited by compound $\mathbf{4 h}$ showing inhibition zone $1.00-5.00 \mathrm{~mm}$ at highest concentration. Less reaction time, high yields of desired products, mild reaction conditions, simple work-up, cost effectiveness and no need of column chromatography are some beauties of present methodology.

\section{Introduction}

Recently application of green chemistry for the formation of potential bioactive heterocyclic moiety has turned out the key area of research for organic chemist due to growing concern over environmental issues ${ }^{1}$. Therefore, the development of non-hazardous synthetic protocol gained the particular attention of synthetic chemist as frontier task in present scenario ${ }^{2-3}$. Lately multi-component reactions (MCRs) are important approach in organic chemistry in which a single operation is enough to form desired product from the well-defined condensation of three or more substrate molecules ${ }^{4}$. Therefore, multi-component reactions has emerged as a clean and facile route for synthesis of potential bioactive heterocyclic compounds and preferred over the stepwise synthetic methods. The beauty of multi-component reactions is eco-friendly nature, less time consumption, excellent atom economy, no need of column chromatography, minimum waste disposal etc ${ }^{5}$. Isoxazole moieties are important class of heterocyclic compounds and they are more abundant in nature and show wide range of biological and pharmaceutical activities such as $\beta$-adrenergic receptor antagonists, immunosuppressive, antiinflammatory, antibacterial, HDAC inhibitors, antifungal, antitumor, antioxidant, antiprotozoal, antiviral, anti-tubercular, anti-HIV, analgesic and anti-androgens (II) $)^{6-20}$. highly potent biological activities, isoxazole derivatives are attractive synthetic nucleus for Due to investigation of efficient and green 
synthetic procedure for their synthesis. Our earlier efforts revealed that isoxazole derivatives has been prepared via one-pot three component condensation reaction of $\beta$-ketoesters, hydroxylamine hydrochloride and substituted aldehydes in presence of sodium benzoate, sodium sulphide, sodium silicate, tartaric acid, pyridine, sodium ascorbate, sodium tetraborate and boric acid ${ }^{21}$. But these methods have some limitations such as harsh reaction conditions, expensive procedure, tedious work-up process, less product yield, less atom economy and completion of reaction time was also more. Based on these findings and our on-going efforts towards synthesis of isoxazoles derivatives, in this paper we reported one-pot three components clean and facile synthesis of isoxazole derivatives in presence of fruit juices viz. Cocos nucifera L. juice, Solanum lycopersicum L. juice and Citrus limetta juice. Moderate to excellent product yield, less reaction time, reduce use of strong acids and bases, high atom economy are some merits of present methodology.

\section{Materials And Methods}

All the required chemicals for experiment were purchased from CDH (Central Drug House), SRL (Sisco Research Laboratory) and Sigma-Aldrich and used without purification. Melting points were determined in open head capillaries and are uncorrected. The reaction was monitored by thin layer chromatography. Infrared spectra (4000-350 $\mathrm{cm}^{-1}$ ) of the synthesized compounds were recorded in $\mathrm{KBr}$ pellets on Perkin Elmer FT-IR-R2X spectrophotometer and frequency was expressed in $\mathrm{cm}^{-1}$. The ${ }^{1} \mathrm{HNMR}$ spectra were recorded in $\mathrm{CDCl}_{3}$ or DMSO- $d_{6}$ using tetra methyl silane (TMS) as internal reference on "Brucker Ac 400 $\mathrm{F}^{\prime \prime}(400 \mathrm{MHz})$ nuclear magnetic resonance spectrometer. Elemental analysis was performed using ThermoFinnigan $\mathrm{CHN}$ elemental analyser. The chemical shifts values were quoted in delta (parts per million, ppm).

\section{Preparation of biocatalyst}

Extraction of Cocos nucifera L. juice: The main ingredients per $100 \mathrm{~g}$ of coconut juice of Cocos nucifera are water $(94.99 \mathrm{~g})$, carbohydrates $(3.71 \mathrm{~g})$, protein $(0.72 \mathrm{~g})$, fat $(0.2 \mathrm{~g})$, ascorbic acid $(2.4 \mathrm{mg})$ and pantothenic acid $(0.043 \mathrm{mg})$. Coconut juice also contains many natural occurring bioactive enzymes such as acid phosphatase, catalase, dehydrogenase, diastase, peroxidase, RNA-polymerase etc. Due to presence of ascorbic acid and pantothenic acid, coconut juice is weakly acidic in nature. The coconut juice was obtained by perforating the fruit with a knife. The coconut juice was filtered using filter paper Whatman no 1 for the elimination of residues to get clear juice which was used as a catalyst ${ }^{22}$.

Preparation of Solanum lycopersicum L. juice: The main constituents per $100 \mathrm{~g}$ of Solanum lycopersicum L. juice are water $(94.24 \mathrm{~g})$, carbohydrates $(3.53 \mathrm{~g})$, protein $(0.85 \mathrm{~g})$, fat $(0.29 \mathrm{~g})$, ascorbic acid $(70.1 \mathrm{mg})$, sugars $(2.58 \mathrm{~g})$ and dietary fibre $(0.4 \mathrm{~g})$. Fresh tomatoes were purchased from the local market. Then washed thoroughly under running tap water followed by rinsing thrice with double distilled water. Tomatoes were squeezed and juice were strained initially through a muslin cloth then passed through Whatman filter paper No. $1^{23}$. 
Preparation of Citrus limetta juice: Citrus limetta is a species of citrus. It contains high amount of ascorbic acid due to which it acts as acid catalyst in organic synthesis. First of all wash the sweet limes and pat them dry. Cut them into two halves. Then using a citrus juice squeezer, extract the juice. Then the juice was filtered through cotton and then through Whatman filter paper no 1 to remove solid material and to get clear juice which as used as a catalyst.

\section{General method for the synthesis of substituted isoxazole derivatives (4a-4h)}

A mixture of hydroxylamine hydrochloride $(20 \mathrm{mmol})$ (3a), methyl acetoacetate (20 mmol) (2a), and Cocos nucifera L. juice/ Solanum lycopersicum L. juice/ Citrus limetta juice in $20 \mathrm{~mL}$ water: ethanol (19:1, $\mathrm{v} / \mathrm{v}$ ) was stirred at room temperature for $15 \mathrm{~min}$, then substituted aldehydes (20 mmol) (1a-1h) was added to mixture (Scheme 1). The reaction mixture was stirred at room temperature until the reaction was completed. The reaction was monitored by thin layer chromatography. After completion of reaction, the precipitate was separated by simple filtration and washed with cold distilled water and dried in the air. Crude products were recrystallized from methanol to afford the pure compounds ( $4 a-4 h)$. The identity of known products was confirmed by comparison of their spectroscopic data and physical properties with those available in recent articles. The novel products were identified by spectral techniques i.e. FTIR, ${ }^{1} \mathrm{HNMR}$ and $\mathrm{CHN}$ analysis. Screening of herbicidal activity

Solutions of $50 \mu \mathrm{g} / \mathrm{mL}, 100 \mu \mathrm{g} / \mathrm{mL}, 150 \mu \mathrm{g} / \mathrm{mL}$ and $200 \mu \mathrm{g} / \mathrm{mL}$ of the test compounds in DMSO were prepared. Agar powder $(5 \mathrm{gm})$ was put into boiling distilled water $(1 \mathrm{~L})$ until it dissolved, and then cooled down to $40-50^{\circ} \mathrm{C}$. The solution $(2 \mathrm{~mL})$ containing test compounds and melting agar $(18 \mathrm{~mL})$ was mixed and this mixture was added to a petridish with $4.5 \mathrm{~cm}$ diameter. The agar plate without test compound was used as an untreated control. The 15 seeds of Raphanus sativus L. (Radish) were put on the surface of the agar plate. The Petridishes were covered with glass lids, and the cultivation conditions were kept at $25 \pm 1^{\circ} \mathrm{C}$ and 12 hours in light and 12 hours in dark alternating for seven days. Seven days later, the root lengths and shoot lengths of Raphanus sativus $\mathrm{L}$. were measured. The growth inhibitory rate related to untreated control was determined by given formula.

$$
\% \text { Inhibition }=\frac{\text { Control }- \text { Treated }}{\text { Control }} \times 100
$$

\section{Screening of antifungal activity}

Amongst the several methods available, poisoned food technique ${ }^{24}$ which is the most common was used for testing antifungal activity. The test fungus was grown on Potato dextrose agar medium. The required amount of synthesized compounds dissolved in $1 \mathrm{~mL}$ of DMSO was incorporated aseptically into $99 \mathrm{~mL}$ aliquots of sterilized potato dextrose agar cooled at $45^{\circ} \mathrm{C}$ after brief shaking. Each lot of medium was poured into Petri dishes and allowed to solidify. $1 \mathrm{~mL}$ DMSO in media was taken as control. Each dish was inoculated centrally with a $5 \mathrm{~mm}$ mycelial disc cut from the periphery of 2-3 days old fungal colonies. Inoculated Petri plates were incubated in the dark $25 \pm 2^{\circ} \mathrm{C}$ for $48-72 \mathrm{~h}$ and colony diameters 
were measured periodically till the control dishes were nearly completely covered with fungus growth. Three replicates were used for each concentration of a chemical together with three dishes containing only the solvent and no toxicant. The degree of inhibition of growth was calculated from the mean differences between treatments and the control as percentage of latter by using the formula.

\section{$\%$ inhibition $=\frac{\text { Control }- \text { Treated }}{\text { Control }} \times 100$}

Control = mycelial growth in control dish

Treated $=$ mycelial growth in treated dish

\section{Screening of antibacterial activity}

The inhibition zone method ${ }^{25}$ was followed for screening the synthesized compounds for their antibacterial activity. The bacterial suspension was prepared from $48 \mathrm{~h}$ old culture. The bacterial growth from five slants was taken and mixed in $100 \mathrm{~mL}$ sterilized distilled water aseptically. The medium was melted and cooled at $45^{\circ} \mathrm{C}$, needed medium was poured aseptically in sterilized Petri plates and rotated gently for even distribution of the medium and was allowed to solidify. 250, 500, 1000 and $2000 \mu \mathrm{g} / \mathrm{mL}$ concentrations of synthesized compounds were prepared from the stock solution by taking appropriate amount and diluting with DMSO. The circular paper discs of $10 \mathrm{~mm}$ diameter were prepared from Whatman's Filter paper No. 1. The disc were kept in Petri plate and autoclaved at $15 \mathrm{lbs}$ pressure 20 minutes. Two paper discs were used for each concentration of the synthesized compounds. The excess of solution absorbed by paper discs was removed by holding them vertically by sterile forecep. Such soaked discs were transferred aseptically to Petri plates containing media and bacterial suspension spread over the surface. Each concentration and chemical was replicated 3 times. Such Petri plates were inverted and kept at $5^{\circ} \mathrm{C}$ for two hour for better diffusion of the chemicals in agar medium. Later, on the Petri plates were incubated at $25 \pm 2^{\circ} \mathrm{C}$ for $48 \mathrm{~h}$. The zone of inhibition for each concentration of the chemicals was recorded in $\mathrm{mm}$ after $48 \mathrm{~h}$ of incubation.

\section{Statistical analysis}

The experiments were performed in triplicates for each treatment and the mean value were recorded and expressed as mean \pm S.D. The descriptive statistics in form of box-and-whisker diagram were also presented in this paper. The spacing between the different parts of the box indicates the degree of dispersion and skewness in the data.

\section{Results And Discussion}

Initially, for optimization the reaction of hydroxylamine hydrochloride $(20 \mathrm{mmol})$, methyl acetoacetate (20 $\mathrm{mmol})$ in $20 \mathrm{~mL}$ water: ethanol $(19: 1, \mathrm{v} / \mathrm{v})$ was stirred at room temperature for $15 \mathrm{~min}$, then 4-Hydroxy-3methoxybenzaldehyde was added to mixture (Scheme 1). 
First, we performed model reaction in presence of Cocos nucifera L. juice at room temperature. We found that when the amount of Cocos nucifera L. juice was only $4.0 \mathrm{~mL}$ in reaction mixture then yield of reaction was less (78\%) and completion of reaction time was also more (Table 1, Entry 1 ). Than we increase the amount of Cocos nucifera L. i.e. $6.0 \mathrm{~mL}, 8.0 \mathrm{~mL}$ and $10.0 \mathrm{~mL}$ respectively and we observed maximum yield of product (92\%) and reaction time was also less (Table1, Entry 4). After having these encouraging results, next we explored the same model reaction in presence of Solanum lycopersicum $\mathrm{L}$. juice and Citrus limetta juice. We observed that maximum yield (90\%) (Table 1, Entry 4), and (95\%) (Table 1, Entry 4) was obtained in presence of Solanum lycopersicum L. juice $(10.0 \mathrm{~mL})$ and Citrus limetta juice $(10.0 \mathrm{~mL})$ respectively. With these optimized conditions, further we explored the substrate scope of this methodology by varying substituted benzaldehyde. In this paper, we reported the synthesis of substituted isoxazoles (4a-4h) by one-pot multicomponent reaction between equimolar substituted aldehydes (1a-1h) viz. 4-Chlorobenzaldehyde, 3,4-Dimethoxybenzaldehyde, 4-Methoxybenzaldehyde, 3-

Hydroxybenzaldehyde, 2-Hydroxybenzaldehyde, 4-Bromobenzaldehyde, 3,4-Dihydroxybenzaldehyde, 3,4,5Trimethoxybenzaldehyde and methyl acetoacetate (2a) and hydroxylamine hydrochloride (3a) in presence of green catalyst viz. Cocos nucifera L. juice, Solanum lycopersicum L. juice and Citrus limetta juice at room temperature (Scheme 1). The physical data of this study were presented in Table 2. All the synthesized compounds were fully characterized by FTIR, 'HNMR and CHN spectral techniques. All synthesized compounds (4a-4h) were shown in Fig 1. In order to show the beauty of current protocol, the previous protocols and their yields for the synthesis were summarized in Table 3. We observed that Cocos nucifera L. juice, Solanum lycopersicum L. juice and Citrus limetta juice catalyst gives the best catalytic activity in terms of product yield and reaction time as compared to other catalysts in literature. Therefore the present procedure for synthesis of isoxazole derivatives is considered as sustainable and eco-friendly protocol.

The possible mechanism for the formation of substituted isoxazole derivatives is shown in Scheme 2 . According to this mechanism first of all there is formation of cyclized adduct (A) by the nucleophilic attack of the amino group and hydroxyl group of hydroxylamine hydrochloride to the carbonyl carbon of methyl acetoacetate in presence of Cocos nucifera L. juice, Solanum lycopersicum L. juice and Citrus limetta juice. The aldehyde was attacked on the cyclized adduct (A) and subsequent Knoevenagel adduct (4a-4h) is formed via removal of the water molecule.

Table 1: Model reaction of 4-Hydroxy-3-methoxybenzaldehyde (20 $\mathrm{mmol})$, methyl acetoacetate (20 mmol) and hydroxylamine hydrochloride $(20 \mathrm{mmol})$ using Cocos nucifera L. juice, Solanum lycopersicum L. juice and Citrus limetta juice as catalyst 


\begin{tabular}{cccccccc}
\hline Entry & $\begin{array}{c}\text { Catalyst Concentration } \\
(\mathrm{mL})\end{array}$ & \multicolumn{2}{c}{ Method A } & \multicolumn{2}{c}{ Method B } & \multicolumn{2}{c}{ Method C } \\
& & $\begin{array}{c}\text { Time } \\
(\mathrm{h})\end{array}$ & $\begin{array}{c}\text { Yield } \\
(\%)\end{array}$ & $\begin{array}{c}\text { Time } \\
(\mathrm{h})\end{array}$ & $\begin{array}{c}\text { Yield } \\
(\%)\end{array}$ & $\begin{array}{c}\text { Time } \\
(\mathrm{h})\end{array}$ & $\begin{array}{c}\text { Yield } \\
(\%)\end{array}$ \\
\hline 1 & 4.0 & 15 & 78 & 13 & 78 & 11 & 85 \\
2 & 6.0 & 13 & 84 & 9 & 85 & 6 & 90 \\
3 & 8.0 & 11 & 90 & 6 & 88 & 5 & 92 \\
$\mathbf{4}$ & $\mathbf{1 0 . 0}$ & $\mathbf{7}$ & $\mathbf{9 2}$ & $\mathbf{4}$ & $\mathbf{9 0}$ & $\mathbf{4}$ & $\mathbf{9 5}$ \\
\hline
\end{tabular}

Table 2: Physical data of substituted isoxazole derivatives (4a-4h)

\begin{tabular}{|c|c|c|c|c|c|c|c|c|c|}
\hline \multirow[t]{2}{*}{ Products } & \multirow[t]{2}{*}{$\mathrm{Ar}$} & \multirow[t]{2}{*}{$\mathrm{R}^{1}$} & \multicolumn{2}{|c|}{ Method A } & \multicolumn{2}{|c|}{ Method B } & \multicolumn{2}{|c|}{ Method C } & \multirow[t]{2}{*}{ M.pt. $\left({ }^{\circ} \mathrm{C}\right)$} \\
\hline & & & $\begin{array}{l}\text { Time } \\
\text { (h) }\end{array}$ & $\begin{array}{c}\text { Yield } \\
\text { (\%) }\end{array}$ & $\begin{array}{l}\text { Time } \\
\text { (h) }\end{array}$ & $\begin{array}{c}\text { Yield } \\
\text { (\%) }\end{array}$ & $\begin{array}{l}\text { Time } \\
\text { (h) }\end{array}$ & $\begin{array}{c}\text { Yield } \\
\text { (\%) }\end{array}$ & \\
\hline $4 a$ & $\mathrm{Ph}-\mathrm{Cl}$ & $\mathrm{CH}_{3}$ & 10 & 80 & 7 & 76 & 8 & 89 & $185-187$ \\
\hline $4 b$ & $\begin{array}{c}\mathrm{Ph}- \\
\left(\mathrm{OCH}_{3}\right)_{2}\end{array}$ & $\mathrm{CH}_{3}$ & 8 & 81 & 6 & 89 & 10 & 90 & $\begin{array}{c}210-212 \text {, (Lit., } \\
210-211)^{26}\end{array}$ \\
\hline $4 \mathrm{c}$ & $\begin{array}{l}\mathrm{Ph}- \\
\mathrm{OCH}_{3}\end{array}$ & $\mathrm{CH}_{3}$ & 5 & 92 & 8 & 90 & 8 & 92 & $\begin{array}{c}\text { 172-174, (Lit., } \\
173-175)^{24}\end{array}$ \\
\hline $4 d$ & $\mathrm{Ph}-\mathrm{OH}$ & $\mathrm{CH}_{3}$ & 6 & 90 & 7 & 92 & 8 & 83 & $\begin{array}{c}\text { 200-202, (Lit., } \\
200-201)^{27}\end{array}$ \\
\hline $4 e$ & $\mathrm{Ph}-\mathrm{OH}$ & $\mathrm{CH}_{3}$ & 8 & 85 & 5 & 80 & 4 & 80 & $\begin{array}{c}\text { 198-200, (Lit., } \\
200-201)^{27}\end{array}$ \\
\hline $4 f$ & $\mathrm{Ph}-\mathrm{Br}$ & $\mathrm{CH}_{3}$ & 7 & 80 & 6 & 78 & 8 & 76 & $178-180$ \\
\hline $4 \mathrm{~g}$ & $\begin{array}{l}\text { Ph- } \\
(\mathrm{OH})_{2}\end{array}$ & $\mathrm{CH}_{3}$ & 5 & 78 & 4 & 94 & 10 & 81 & $\begin{array}{c}210-211 \text {, (Lit., } \\
212-214)^{26}\end{array}$ \\
\hline $4 h$ & $\begin{array}{c}\mathrm{Ph}- \\
\left(\mathrm{OCH}_{3}\right)_{3}\end{array}$ & $\mathrm{CH}_{3}$ & 6.5 & 82 & 4 & 91 & 6 & 82 & 194-196 \\
\hline
\end{tabular}

Table 3: Comparison for different catalysts used for synthesis of isoxazole derivatives (4a-4h) 


\begin{tabular}{|c|c|c|c|c|c|c|}
\hline S.No. & Catalyst & Solvent & $\begin{array}{c}\text { Temperature } \\
\left({ }^{\circ} \mathrm{C}\right)\end{array}$ & $\begin{array}{l}\text { Time } \\
(\min )\end{array}$ & $\begin{array}{c}\text { Yield } \\
(\%)\end{array}$ & References \\
\hline 1 & $\begin{array}{c}\text { Sodium benzoate (15 } \\
\text { mol\%) }\end{array}$ & Water & RT & 60 & 85 & 28 \\
\hline 2 & Saccharose (20 mol\%) & Solvent-free & $100{ }^{\circ} \mathrm{C}$ & 10 & 75 & 29 \\
\hline 3 & $\begin{array}{c}\text { Cetyltrimethylammonium } \\
\text { chloride (30 mol\%) }\end{array}$ & Water & $90^{\circ} \mathrm{C}$ & 240 & 89 & 30 \\
\hline 4 & Nano-ZnO (5 mol\%) & Water & $70^{\circ} \mathrm{C}$ & 60 & 94 & 31 \\
\hline 5 & Nano-CuI (1.2 mol\%) & Water & Reflux & 40 & 90 & 32 \\
\hline 6 & TBABr (10 mol \%) & Water & Reflux & 15 & 90 & 33 \\
\hline 7 & -Alumina (30 mol\%) & Water & Reflux & 50 & 80 & 34 \\
\hline 8 & $\beta$-Cyclodextrin (10 mol\%) & $\begin{array}{l}\text { Water-ethanol } \\
\qquad(9: 1, V / v)\end{array}$ & $80^{\circ} \mathrm{C}$ & 15 & 92 & 35 \\
\hline 9 & Urea (10 mol\%) & $\begin{array}{l}\text { Water-ethanol } \\
\qquad(1: 1, V / v)\end{array}$ & RT & 480 & 86 & 36 \\
\hline 10 & DABCO (5 mol\%) & Water & Reflux & 15 & 92 & 37 \\
\hline 11 & DCDBTSD (10 mol\%) & Water & $80^{\circ} \mathrm{C}$ & 60 & 85 & 38 \\
\hline 12 & [Bmim]OH (20 mol\%) & Solvent-free & $50-60{ }^{\circ} \mathrm{C}$ & 45 & 90 & 39 \\
\hline 13 & Cocos nucifera L. juice & $\begin{array}{c}\text { Water : } \\
\text { ethanol } \\
(19: 1, V / v)\end{array}$ & RT & 4 & 90 & $\begin{array}{l}\text { Present } \\
\text { work }\end{array}$ \\
\hline 14 & $\begin{array}{c}\text { Solanum lycopersicum L. } \\
\text { juice }\end{array}$ & $\begin{array}{c}\text { Water : } \\
\text { ethanol } \\
(19: 1, V / v)\end{array}$ & RT & 7 & 92 & $\begin{array}{l}\text { Present } \\
\text { work }\end{array}$ \\
\hline 15 & Citrus limetta juice & $\begin{array}{c}\text { Water : } \\
\text { ethanol } \\
(19: 1, V / v)\end{array}$ & RT & 4 & 95 & $\begin{array}{l}\text { Present } \\
\text { work }\end{array}$ \\
\hline
\end{tabular}

Table 4: Herbicidal activity of substituted isoxazoles (4a-4h) 


\begin{tabular}{|c|c|c|c|c|c|c|c|c|}
\hline \multirow[t]{3}{*}{ Compounds } & \multicolumn{8}{|c|}{ Growth Inhibition (\%) } \\
\hline & \multicolumn{4}{|c|}{ Root } & \multicolumn{4}{|c|}{ Shoot } \\
\hline & $\begin{array}{c}50 \\
(\mu \mathrm{g} / \mathrm{mL})\end{array}$ & $\begin{array}{c}100 \\
(\mu \mathrm{g} / \mathrm{mL})\end{array}$ & $\begin{array}{c}150 \\
(\mu \mathrm{g} / \mathrm{mL})\end{array}$ & $\begin{array}{c}200 \\
(\mu \mathrm{g} / \mathrm{mL})\end{array}$ & $\begin{array}{c}50 \\
(\mu \mathrm{g} / \mathrm{mL})\end{array}$ & $\begin{array}{c}100 \\
(\mu \mathrm{g} / \mathrm{mL})\end{array}$ & $\begin{array}{c}150 \\
(\mu \mathrm{g} / \mathrm{mL})\end{array}$ & $\begin{array}{c}200 \\
(\mu \mathrm{g} / \mathrm{mL})\end{array}$ \\
\hline $4 a$ & $\begin{array}{c}36.66 \pm \\
1.14\end{array}$ & $\begin{array}{c}53.33 \pm \\
1.07\end{array}$ & $\begin{array}{c}63.33 \pm \\
0.87\end{array}$ & $\begin{array}{c}73.33 \pm \\
0.67\end{array}$ & $\begin{array}{c}64.61 \pm \\
1.21\end{array}$ & $\begin{array}{c}69.23 \pm \\
0.93\end{array}$ & $\begin{array}{c}75.38 \pm \\
1.95\end{array}$ & $\begin{array}{c}80.00 \pm \\
0.83\end{array}$ \\
\hline $4 b$ & $\begin{array}{c}46.66 \pm \\
0.93\end{array}$ & $\begin{array}{c}66.60 \pm \\
0.90\end{array}$ & $\begin{array}{c}80.00 \pm \\
0.50\end{array}$ & $\begin{array}{c}90.00 \pm \\
1.46\end{array}$ & $\begin{array}{c}67.69 \pm \\
1.11\end{array}$ & $\begin{array}{c}76.92 \pm \\
1.27\end{array}$ & $\begin{array}{c}86.15 \pm \\
0.89\end{array}$ & $\begin{array}{c}93.84 \pm \\
1.18\end{array}$ \\
\hline $4 \mathrm{c}$ & $\begin{array}{c}34.36 \pm \\
0.72\end{array}$ & $\begin{array}{c}48.36 \pm \\
0.49\end{array}$ & $\begin{array}{c}61.45 \pm \\
0.75\end{array}$ & $\begin{array}{c}78.65 \pm \\
0.55\end{array}$ & $\begin{array}{c}51.39 \pm \\
0.80\end{array}$ & $\begin{array}{c}62.36 \pm \\
0.78\end{array}$ & $\begin{array}{c}71.45 \pm \\
1.48\end{array}$ & $\begin{array}{c}82.36 \pm \\
0.99\end{array}$ \\
\hline $4 d$ & $\begin{array}{c}43.33 \pm \\
0.40\end{array}$ & $\begin{array}{c}60.00 \pm \\
1.75\end{array}$ & $\begin{array}{c}73.33 \pm \\
0.40\end{array}$ & $\begin{array}{c}86.66 \pm \\
0.50\end{array}$ & $\begin{array}{c}67.69 \pm \\
1.12\end{array}$ & $\begin{array}{c}76.92 \pm \\
1.27\end{array}$ & $\begin{array}{c}84.61 \pm \\
0.94\end{array}$ & $\begin{array}{c}90.76 \pm \\
1.23\end{array}$ \\
\hline $4 e$ & $\begin{array}{c}40.52 \pm \\
1.06\end{array}$ & $\begin{array}{c}58.37 \pm \\
0.99\end{array}$ & $\begin{array}{c}74.50 \pm \\
0.50\end{array}$ & $\begin{array}{c}88.24 \pm \\
1.00\end{array}$ & $\begin{array}{c}49.92 \pm \\
1.05\end{array}$ & $\begin{array}{c}68.28 \pm \\
0.97\end{array}$ & $\begin{array}{c}78.36 \pm \\
0.99\end{array}$ & $\begin{array}{c}90.25 \pm \\
0.94\end{array}$ \\
\hline $4 f$ & $\begin{array}{c}35.69 \pm \\
0.43\end{array}$ & $\begin{array}{c}45.48 \pm \\
0.44\end{array}$ & $\begin{array}{c}60.36 \pm \\
1.52\end{array}$ & $\begin{array}{c}72.58 \pm \\
1.32\end{array}$ & $\begin{array}{c}41.30 \pm \\
1.24\end{array}$ & $\begin{array}{c}54.78 \pm \\
1.52\end{array}$ & $\begin{array}{c}71.13 \pm \\
1.01\end{array}$ & $\begin{array}{c}85.48 \pm \\
1.51\end{array}$ \\
\hline $4 \mathrm{~g}$ & $\begin{array}{c}36.66 \pm \\
1.57\end{array}$ & $\begin{array}{c}50.00 \pm \\
0.82\end{array}$ & $\begin{array}{c}63.33 \pm \\
0.68\end{array}$ & $\begin{array}{c}76.66 \pm \\
0.82\end{array}$ & $\begin{array}{c}60.00 \pm \\
0.66\end{array}$ & $\begin{array}{c}66.15 \pm \\
1.00\end{array}$ & $\begin{array}{c}75.38 \pm \\
2.09\end{array}$ & $\begin{array}{c}81.53 \pm \\
1.14\end{array}$ \\
\hline $4 \mathrm{~h}$ & $\begin{array}{c}43.33 \pm \\
0.98\end{array}$ & $\begin{array}{c}63.33 \pm \\
1.47\end{array}$ & $\begin{array}{c}76.66 \pm \\
0.97\end{array}$ & $\begin{array}{c}86.66 \pm \\
0.92\end{array}$ & $\begin{array}{c}75.38 \pm \\
0.95\end{array}$ & $\begin{array}{c}81.53 \pm \\
1.56\end{array}$ & $\begin{array}{c}84.61 \pm \\
1.10\end{array}$ & $\begin{array}{c}89.23 \pm \\
0.94\end{array}$ \\
\hline
\end{tabular}

All values are mean \pm S.D.

Table 5: Antifungal activity of substituted isoxazoles (4a-4h) 


\section{Fungi}

Rhizoctonia solani (conc.) $\mu \mathrm{g} / \mathrm{mL} \quad$ Colletotrichum gloeosporioides (conc.) $\mu \mathrm{g} / \mathrm{mL}$

\begin{tabular}{ccccc|cccc} 
& $\mathbf{2 5 0}$ & $\mathbf{5 0 0}$ & $\mathbf{1 0 0 0}$ & $\mathbf{2 0 0 0}$ & $\mathbf{2 5 0}$ & $\mathbf{5 0 0}$ & $\mathbf{1 0 0 0}$ & $\mathbf{2 0 0 0}$ \\
\hline $\mathbf{4 a}$ & $12.50 \pm$ & $27.50 \pm$ & $52.50 \pm$ & $75.00 \pm$ & $10.23 \pm$ & $24.62 \pm$ & $48.75 \pm$ & $70.23 \pm$ \\
& 1.07 & 0.59 & 0.71 & 0.72 & 0.68 & 1.58 & 0.69 & 0.43 \\
$\mathbf{4 b}$ & $56.00 \pm$ & $64.00 \pm$ & $76.00 \pm$ & $90.00 \pm$ & $36.45 \pm$ & $58.45 \pm$ & $70.23 \pm$ & $82.45 \pm$ \\
& 0.82 & 1.06 & 1.17 & 2.35 & 0.86 & 0.95 & 1.51 & 1.04 \\
$\mathbf{4 c}$ & $42.00 \pm$ & $56.00 \pm$ & $80.00 \pm$ & $90.00 \pm$ & $30.25 \pm$ & $51.36 \pm$ & $66.60 \pm$ & $79.65 \pm$ \\
& 1.37 & 0.87 & 0.66 & 1.26 & 0.73 & 1.01 & 0.67 & 0.95 \\
$\mathbf{4 d}$ & $\mathrm{a}$ & $\mathrm{a}$ & $\mathrm{a}$ & $\mathrm{a}$ & $\mathrm{a}$ & $\mathrm{a}$ & $36.68 \pm$ & $51.78 \pm$ \\
& & & & & & 0.62 & 1.09 \\
$\mathbf{4 e}$ & $20.75 \pm$ & $58.49 \pm$ & $66.03 \pm$ & $84.90 \pm$ & $\mathrm{a}$ & $\mathrm{a}$ & $\mathrm{a}$ & $\mathrm{a}$ \\
& 1.44 & 1.06 & 0.56 & 0.77 & & & & \\
$\mathbf{4 f}$ & $\mathrm{a}$ & $\mathrm{a}$ & $48.12 \pm$ & $74.96 \pm$ & $\mathrm{a}$ & $\mathrm{a}$ & $24.56 \pm$ & $42.98 \pm$ \\
& & & 1.12 & 2.50 & & & 1.58 & 1.30 \\
$\mathbf{4 g}$ & $23.98 \pm$ & $56.42 \pm$ & $68.45 \pm$ & $87.36 \pm$ & $14.25 \pm$ & $29.35 \pm$ & $48.68 \pm$ & $68.45 \pm$ \\
& 0.93 & 0.54 & 0.69 & 0.75 & 0.52 & 1.55 & 0.35 & 0.52 \\
$\mathbf{4 h}$ & $45.23 \pm$ & $58.69 \pm$ & $81.35 \pm$ & $91.23 \pm$ & $25.12 \pm$ & $47.98 \pm$ & $61.89 \pm$ & $74.30 \pm$ \\
& 1.29 & 1.01 & 2.09 & 0.72 & 0.75 & 0.87 & 2.19 & 1.44 \\
\hline
\end{tabular}

All values are mean \pm S.D.

\section{a: No Growth Inhibition}

Table 6: Antibacterial activity of substituted isoxazoles (4a-4h) 
Bacteria

\begin{tabular}{|c|c|c|c|c|c|c|c|c|}
\hline & \multicolumn{4}{|c|}{ Erwinia carotovora (conc.) $\mu \mathrm{g} / \mathrm{mL}$} & \multicolumn{4}{|c|}{ Xanthomonas citri (conc.) $\mathrm{\mu g} / \mathrm{mL}$} \\
\hline & 250 & 500 & 1000 & 2000 & 250 & 500 & 1000 & 2000 \\
\hline $4 a$ & $\mathrm{a}$ & $\begin{array}{c}1.00 \pm \\
0.05\end{array}$ & $\begin{array}{c}2.00 \pm \\
0.25\end{array}$ & $\begin{array}{c}3.00 \pm \\
0.45\end{array}$ & $\begin{array}{c}0.30 \pm \\
0.03\end{array}$ & $\begin{array}{c}0.70 \pm \\
0.05\end{array}$ & $\begin{array}{c}1.00 \pm \\
0.12\end{array}$ & $\begin{array}{c}1.30 \pm \\
0.15\end{array}$ \\
\hline $4 b$ & $\begin{array}{c}1.50 \pm \\
0.20\end{array}$ & $\begin{array}{c}2.20 \pm \\
0.05\end{array}$ & $\begin{array}{c}3.00 \pm \\
0.15\end{array}$ & $\begin{array}{c}4.00 \pm \\
0.15\end{array}$ & $\mathrm{a}$ & $\mathrm{a}$ & $\mathrm{a}$ & a \\
\hline $4 c$ & $\mathrm{a}$ & $\mathrm{a}$ & $\begin{array}{c}2.00 \pm \\
0.15\end{array}$ & $\begin{array}{c}5.00 \pm \\
0.45\end{array}$ & $\mathrm{a}$ & $\begin{array}{c}1.00 \pm \\
0.12\end{array}$ & $\begin{array}{c}2.00 \pm \\
0.13\end{array}$ & $\begin{array}{c}3.00 \pm \\
0.13\end{array}$ \\
\hline $4 d$ & $\mathrm{a}$ & $\begin{array}{c}1.00 \pm \\
0.05\end{array}$ & $\begin{array}{c}2.50 \pm \\
0.25\end{array}$ & $\begin{array}{c}4.00 \pm \\
0.40\end{array}$ & $\mathrm{a}$ & $\mathrm{a}$ & $\mathrm{a}$ & $\begin{array}{c}0.50 \pm \\
0.02\end{array}$ \\
\hline $4 e$ & $\mathrm{a}$ & $\mathrm{a}$ & $\mathrm{a}$ & $\mathrm{a}$ & a & a & $\mathrm{a}$ & $\mathrm{a}$ \\
\hline $4 f$ & $\begin{array}{c}0.70 \pm \\
0.07\end{array}$ & $\begin{array}{c}1.00 \pm \\
0.01\end{array}$ & $\begin{array}{c}1.60 \pm \\
0.20\end{array}$ & $\begin{array}{c}2.10 \pm \\
0.25\end{array}$ & $\begin{array}{c}0.10 \pm \\
0.01\end{array}$ & $\begin{array}{c}0.30 \pm \\
0.02\end{array}$ & $\begin{array}{c}0.60 \pm \\
0.04\end{array}$ & $\begin{array}{c}0.70 \pm \\
0.07\end{array}$ \\
\hline $4 \mathrm{~g}$ & $\mathrm{a}$ & $\mathrm{a}$ & $\begin{array}{c}0.60 \pm \\
0.07\end{array}$ & $\begin{array}{c}1.20 \pm \\
0.15\end{array}$ & $\begin{array}{c}2.10 \pm \\
0.20\end{array}$ & $\begin{array}{c}2.60 \pm \\
0.26\end{array}$ & $\begin{array}{c}3.10 \pm \\
0.30\end{array}$ & $\begin{array}{c}3.90 \pm \\
0.47\end{array}$ \\
\hline $4 h$ & $\begin{array}{c}3.00 \pm \\
0.40\end{array}$ & $\begin{array}{c}5.50 \pm \\
0.05\end{array}$ & $\begin{array}{c}7.00 \pm \\
0.45\end{array}$ & $\begin{array}{c}9.60 \pm \\
0.36\end{array}$ & $\begin{array}{c}1.00 \pm \\
0.12\end{array}$ & $\begin{array}{c}2.20 \pm \\
0.20\end{array}$ & $\begin{array}{c}3.00 \pm \\
0.32\end{array}$ & $\begin{array}{c}5.00 \pm \\
0.55\end{array}$ \\
\hline
\end{tabular}

All values are mean \pm S.D. ; a: No Inhibition Zone

Characterization data of selected compounds

(Z)-4-(3,4-Dimethoxybenzylidene)-3-methylisoxazol-5(4H)-one (4b): Elemental Analysis found: $\mathrm{C}, 63.15 ; \mathrm{H}$, 5.30; N, 5.67; O, 25.88; Required: C, 62.89; H, 5.32; N, 5.78

(Z)-4-(4-Methoxybenzylidene)-3-methylisoxazol-5(4H)-one (4c): m.p. $172-174^{\circ} \mathrm{C} ;{ }^{1} \mathrm{H} \mathrm{NMR}(400 \mathrm{MHz}$, DMSO- $\left._{6}\right): \delta 2.25\left(\mathrm{~s}, 3 \mathrm{H}, \mathrm{CH}_{3}\right) ; 3.89\left(\mathrm{~s}, 3 \mathrm{H}, \mathrm{OCH}_{3} ; 7.74(\mathrm{~s}, 1 \mathrm{H},=\mathrm{CH}) ; 7.05-8.50(\mathrm{~m}, 4 \mathrm{H}, \mathrm{Ar}-\mathrm{H}) ; \mathrm{IR}\left(v_{\max } \mathrm{cm}^{-1}\right)\right.$ (neat): $1591.5(\mathrm{C}=\mathrm{N}), 1619.0\left(\mathrm{C}=\mathrm{C}\right.$, aromatic), $1729.9(\mathrm{C}=0) ; 1431.8(\mathrm{~N}-0), 1276.6\left(\mathbf{O C H}_{3}\right)$; Elemental Analysis found: $\mathrm{C}, 66.35 ; \mathrm{H}, 5.10 ; \mathrm{N}, 6.45 ; \mathrm{O}, 22.10$; Required: $\mathrm{C}, 66.33 ; \mathrm{H}, 5.13 ; \mathrm{N}, 6.62$

(Z)-4-(2-Hydroxybenzylidene)-3-methylisoxazol-5(4H)-one (4e): m.p. $198-200^{\circ} \mathrm{C} ;{ }^{1} \mathrm{H} \mathrm{NMR}(400 \mathrm{MHz}$, DMSO- $\left.d_{6}\right): \delta 2.25\left(\mathrm{~s}, 3 \mathrm{H}, \mathrm{CH}_{3}\right) ; 8.20(\mathrm{~s}, 1 \mathrm{H},=\mathrm{CH}) ; 6.87-8.77(\mathrm{~m}, 4 \mathrm{H}, \mathrm{Ar}-\mathrm{H}) ; 10.85(\mathrm{~s}, 1 \mathrm{H}, \mathrm{OH})$

(Z)-4-(4-Bromobenzylidene)-3-methylisoxazol-5(4H)-one (4f): m.p. $178-180^{\circ} \mathrm{C} ;{ }^{1} \mathrm{H} \mathrm{NMR}\left(400 \mathrm{MHz}, \mathrm{CDCl}_{3}\right)$ : $\delta 2.29\left(\mathrm{~s}, 3 \mathrm{H}, \mathrm{CH}_{3}\right) ; 7.37(\mathrm{~s}, 1 \mathrm{H},=\mathrm{CH}) ; 7.59-8.22(\mathrm{~m}, 4 \mathrm{H}, \mathrm{Ar}-\mathrm{H})$

\section{Herbicidal activity}

All synthesized compounds (4a-4h) were screened for herbicidal activity against Raphanus sativus $\mathrm{L}$. at various concentration 200,150, 100 and $50 \mu \mathrm{g} / \mathrm{mL}$ as shown in Table 4. Results were quoted in form of primary screening. Synthesised compounds were diluted to $1000 \mu \mathrm{g} / \mathrm{mL}$ concentration as a stock 
solution. Herbicidal activity of synthesized compounds was evaluated against Raphanus sativus L. by inhibitory effect of the compounds on the growth of weed roots and shoots. The percentage of inhibition of growth was calculated from the mean differences between treated and control. From the herbicidal activity data, we identified that compound (Z)-4-(3,4-Dimethoxybenzylidene)-3-methylisoxazol-5(4H)-one (4b) was most active against Raphanus sativus $L$. seeds. The growth inhibition may be attributed to substitution of methoxy group on phenyl ring. The box plot and graphical representation of herbicidal activity of all synthesized compounds (4a-4h) against Raphanus sativus $\mathrm{L}$. seeds were shown in Figs 2-5.

\section{Antifungal activity}

All synthesized compounds (4a-4h) were tested for their in vitro antifungal activity against Rhizoctonia solani and Colletotrichum gloeosporioides. The percentage growth inhibition of compounds against $R$. Solani and C. Gloeosporioides is presented in Table 5. DMSO was used as control against both the test fungi. A culture of test fungi was grown on Potato Dextrose Agar (PDA) medium at ambient temperature $\left(25 \pm 2^{\circ} \mathrm{C}\right)$. The stock solution $(2000 \mu \mathrm{g} / \mathrm{mL})$ of test compounds were prepared in DMSO and further dilutions were made to 1000,500 and $250 \mu \mathrm{g} / \mathrm{mL}$ concentrations and stored at $4^{\circ} \mathrm{C}$ for further use. Potato dextrose agar media, containing specific concentration of test compounds was poured on Petri plates. After solidification, small disc $(0.5 \mathrm{~cm}$ diameter $)$ of the fungus culture was cut with a sterile cork borer and transferred aseptically upside down in centre of Petri plate. Petri plates were incubated in BOD incubator at $25 \pm 2^{\circ} \mathrm{C}$. Growth of fungal colony was measured after every $24 \mathrm{~h}$ till the fungus in control plates (containing DMSO) completely occupied it. From the fungicidal activity results, we concluded that compound $\mathbf{4} \mathbf{b}$ was most likely against both the fungus viz. $R$. solani and $C$. gloeosporioides respectively. This result may be due to presence of methoxy group on phenyl ring. The box plot and graphical representation of antifungal activity of all synthesized compounds (4a-4h) against Rhizoctonia solani and Colletotrichum gloeosporioides were shown in Figs 6-9.

\section{Antibacterial activity}

All synthesized compounds (4a-4h) were evaluated for their inhibitory effect on the growth of two bacterial species viz. Erwinia carotovora and Xanthomonas citri at various concentrations i.e. 250, 500, 1000 and $2000 \mu \mathrm{g} / \mathrm{mL}$. Luria- Bertani medium was sterilized by auto-claving at 15 psi pressure at $121^{\circ} \mathrm{C}$ for 15 to 20 minutes. The plates were prepared by pouring $30-35 \mathrm{~mL}$ of the sterilized media into sterilized Petri plates. Media was then allowed to solidify and then suspension of 3-4 days old broth of test organism was then spread on specific medium plates. Sterile filter paper discs moistened with test compounds solution in DMSO were carefully placed on the medium inoculated with the specific bacterial suspension. Sterile filter paper discs dipped in DMSO served as control. These plates were incubated at $25 \pm 2^{\circ} \mathrm{C}$ and the diameter of growth inhibition zone was measured after $24 \mathrm{~h}$. The results of antibacterial screening of synthesized compounds (4a-4h) were presented in Table 6 . The results revealed that some of synthesized compounds showed no inhibition against Erwinia carotovora and Xanthomonas citri at all concentrations. Maximum Erwinia carotovora growth was inhibited by compound $\mathbf{4 h}$ showing inhibition 
zone 3.00-9.60 mm. Maximum Xanthomonas citri growth was also inhibited by compound $\mathbf{4 h}$ showing inhibition zone 1.00-5.00 mm. This inhibition may be due to presence of methoxy group on phenyl ring. The box plot and graphical representation of antibacterial activity of all synthesized compounds (4a-4h) against Erwinia carotovora and Xanthomonas citri were shown in Figs 10-13.

\section{Conclusions}

We have developed a novel route for synthesis of biologically active substituted isoxazole derivatives (4a4h) via one-pot three components reaction between substituted aldehydes (1a-1h), methyl acetoacetate (2a) and hydroxylamine hydrochloride (3a) in presence of Cocos nucifera L. juice, Solanum lycopersicum L. juice and Citrus limetta juice. The present protocol offers many advantages such as simple and efficient catalytic system, simple work-up, cost-effective and products were obtained in good to excellent yields. All synthesized compounds were characterized by ${ }^{1} \mathrm{HNMR}$, FTIR and $\mathrm{CHN}$ spectral analysis. All synthesized compounds (4a-4h) were also screened for their bio efficacy in terms of herbicidal activity against Raphanus sativus L. (Radish) seeds, fungicidal activity against $R$. solani, C. gloeosporioides and antibacterial activity against Erwinia carotovora and Xanthomonas citri. Based on activity results, we concluded that good activity of some synthesized compounds due to substitution of methoxy group on phenyl ring. Utilizing fruit juices as catalyst in organic reactions would be more beneficial to academic and industrial researches in near future.

\section{Declarations}

\section{Funding}

Authors received no specific funding for this study. The funder has no role in study design, data collection and analysis, decision to publish or preparation of the manuscript.

\section{Acknowledgements}

The authors are thankful to the Department of Chemistry, Chaudhary Charan Singh Haryana Agricultural University, Hisar for providing the necessary facilities. Financial assistance from Department of Science and Technology (DST), New Delhi, India is gratefully acknowledged. Authors are also thankful to SAIF, Punjab University Chandigarh, for providing analytical facilities for characterization of compounds.

\section{Author Contributions}

Conceptualization: Susheel Gulati, Rajvir Singh

Data curation: Susheel Gulati, Rajvir Singh, Suman Sangwan

Formal analysis: Susheel Gulati, Rajvir Singh, Suman Sangwan

Investigation: Susheel Gulati, Rajvir Singh 
Methodology: Susheel Gulati, Rajvir Singh, Suman Sangwan

Supervision: Susheel Gulati, Rajvir Singh

Validation: Susheel Gulati, Rajvir Singh, Suman Sangwan

Writing-original draft: Susheel Gulati

Writing-review \& editing: Susheel Gulati, Rajvir Singh, Suman Sangwan

\section{References}

1. Balini, R. Eco-friendly synthesis of Fine chemicals, Royal Society of Chemistry, 2009.

2. Anastas, P. T. \& Warner, J. C. Green Chemistry: Theory and Practise first edn (Oxford university Press Inc., New York, 1998).

3. Anastas, P. T. \& Kirchhoff, M. M. Acc. Chem. Res. 35, 686-694 (2002).

4. Zhu, J. \& Bienayme, H. Multicomponent Reactions 1st edn (Weinheim, Germany, Wliley-VCH, 2005).

5. Trost, B. M. Sci. 254, 1471-1477 (1991).

6. Conti, P., Dallanoce, M. D., Amici, M. D., Micheli, C. D. \& Klotz, K. N. Bioorg. Med. Chem. 6, 401 (1998).

7. Gordaliza, M. et al. J. Med. Chem. 39, 2865 (1996).

8. Kwon, T., Heimann, A. S., Oriaku, E. T. \& Yoon, K. J. Med. Chem. 38, 1048 (1995).

9. Kang, Y. K. et al. Bioorg. Med. Chem. Lett. 10, 95 (2000).

10. Kozikowski, A. P., Tapadar, S., Luchini, D. N., Kim, K. H. \& Billadeau, D. D. J. Med. Chem. 51, 4370 (2008).

11. Vicentini, C. V., Romagnoli, C., Manfredini, S., Rossi, D. \& Mares, D. Pharm. Biol. 49, 545 (2011).

12. Reddy, R. K. et al. Bioorg. Med. Chem. Lett. 24, 1661 (2014).

13. Padmaja, A., Rajasekhar, C., Muralikrishna, A. \& Padmavathi, V. Eur. J. Med. Chem. 46, 5034 (2011).

14. Patrick, D. A. et al. R.R. J. Med. Chem. 50, 2468 (2007).

15. Loh, B. et al. Chem. Biol. Drug Des. 75, 461 (2010).

16. Mao, J. et al. J. Med. Chem. 52, 6966 (2009).

17. Deng, B. L. et al. Bioorg. Med. Chem. 14, 2366 (2006).

18. Kano, H., Adachi, I., Kido, R. \& Hirose, K. J. Med. Chem. 10, 411 (1967).

19. Ishioka, T. et al. Bioorg. Med. Chem. 10, 1555 (2002).

20. Ishioka, T., Tanatani, A., Nagasawa, K. \& Hashimoto, Y. Bioorg. Med. Chem. Lett. 13, 2655 (2003).

21. Vekariya, R. H., Patel, K. D. \& Patel, H. D. Res. Chem. Intermed. 42, 75597579 (2016).

22. Fonseca, A. M. et al. J. Mol. Catal. B Enzym. 57, 78-82 (2009).

23. Zia, M. et al. ;IET Nanobiotechnol. 2016,1-7.

24. Groves, R. K. \& Moore, J. D. Phytopathology. 52, 876-880 (1962). 
25. Thornberry, H. H. ; Phytopathology. 1950,40.

26. Maddila, S. N., Maddila, S., Zyl, W. E. \& Jonnalagadda, S. B. Res. Chem. Intermed. https://doi.org/10.1007/s11164-015-2167-2 (2015).

27. Kiyani, H., Jabbari, M., Mosallanezhad, A. \& Ghorbani, F. Res. Chem. Intermed. 41, 7561 (2015).

28. Kiyani, H., Samimi, H. A., Ghorbani, F. \& Esmaieli, S. Curr. Chem. Lett. 2, 197 (2013).

29. Kangani, M. et al. J. Iran. Chem. Soc. 12, 47 (2015).

30. Wu, M., Feng, Q., Wan, H. D. \& Ma, J. Synth. Commun. 43, 1721 (2013).

31. Tekale, S. U., Kauthale, S. S., Jadhav, K. M. \& Pawar, R. P. J. Chem. 1, 2013 (2013).

32. Ghomi, J. S., Ziarati, A. \& Tamimi, M. Acta Chim. Slov. 60, 403 (2013).

33. Kumar, G. S., Kurumurthy, C., Veeraswamy, B., Rao, P. S. \& Narsaiah, B. Org. Prep. Proced. Int. 45, 429 (2013).

34. Mecadon, H., Rohman, M. R., Rajbangshi, M. \& Myrboh, B. Tetrahedron Lett. 52, 2523 (2011).

35. Tayade, Y. A., Padvi, S. A., Wagh, Y. B. \& Dalal, D. S. Tetrahedron Lett. 56, 2441 (2015).

36. Mingshu, W., Qinqin, F., Dehui, W. \& Jinya, M. Synth. Commun. 43, 1721 (2013).

37. Waghmare, A. S. \& Pandit, S. S. J. Saudi Chem. Soc. https://doi.org/10.1016/j.jscs.2015-06.010 (2015).

38. Khazaei, M. A., Zolfigol, M. A., Karimitabar, F., Nikokar, I. \& Zare, M. RSC Adv. 5, 71402 (2015).

39. Khurana, J. M. \& Chaudhary, A. Green Chem. Lett. Rev. 5, 633 (2012).

\section{Figures}


<smiles>CC1=NOC(=O)/C1=C\c1ccc(Cl)cc1</smiles><smiles>COc1ccc(/C=C2/C(=O)ON=C2C)cc1OC</smiles><smiles>COc1ccc(/C=C2\C(=O)ON=C2C)cc1</smiles><smiles>CC1=NOC(=O)/C1=C\c1cccc(O)c1</smiles>

(4d)<smiles>CC1=NOC(=O)/C1=C\c1ccccc1O</smiles>

(4e)<smiles>CC1=NOC(=O)/C1=C\c1ccc(Br)cc1</smiles>

(4f)<smiles>CC1=NOC(=O)/C1=C/c1ccc(O)c(O)c1</smiles><smiles>COc1cc(/C=C2\C(=O)ON=C2C)cc(OC)c1OC</smiles>

Figure 1

Substituted isoxazole derivatives (4a-4h) 


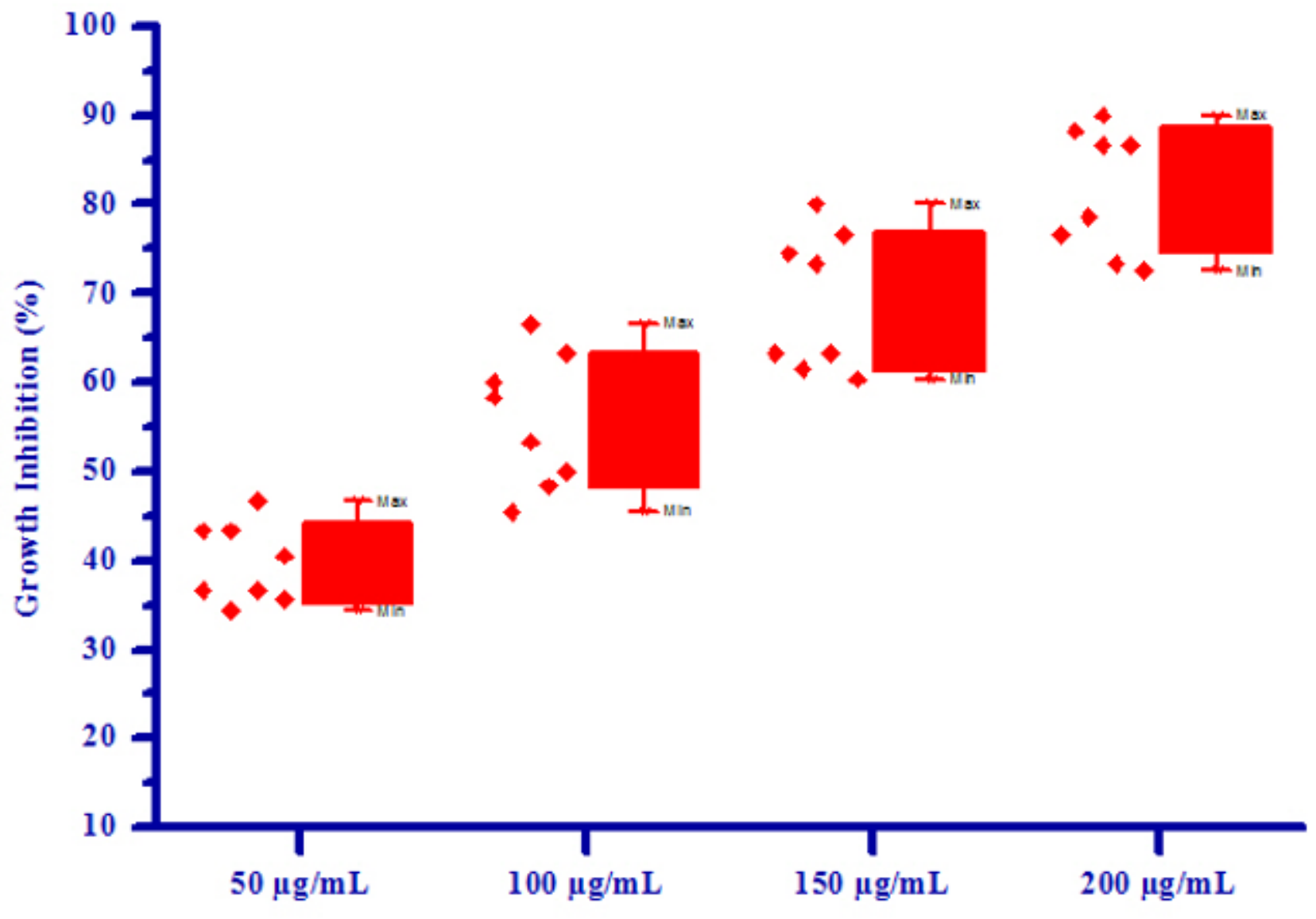

Figure 2

Box plot of substituted isoxazoles (4a-4h) against Raphanus sativus L. (root) 


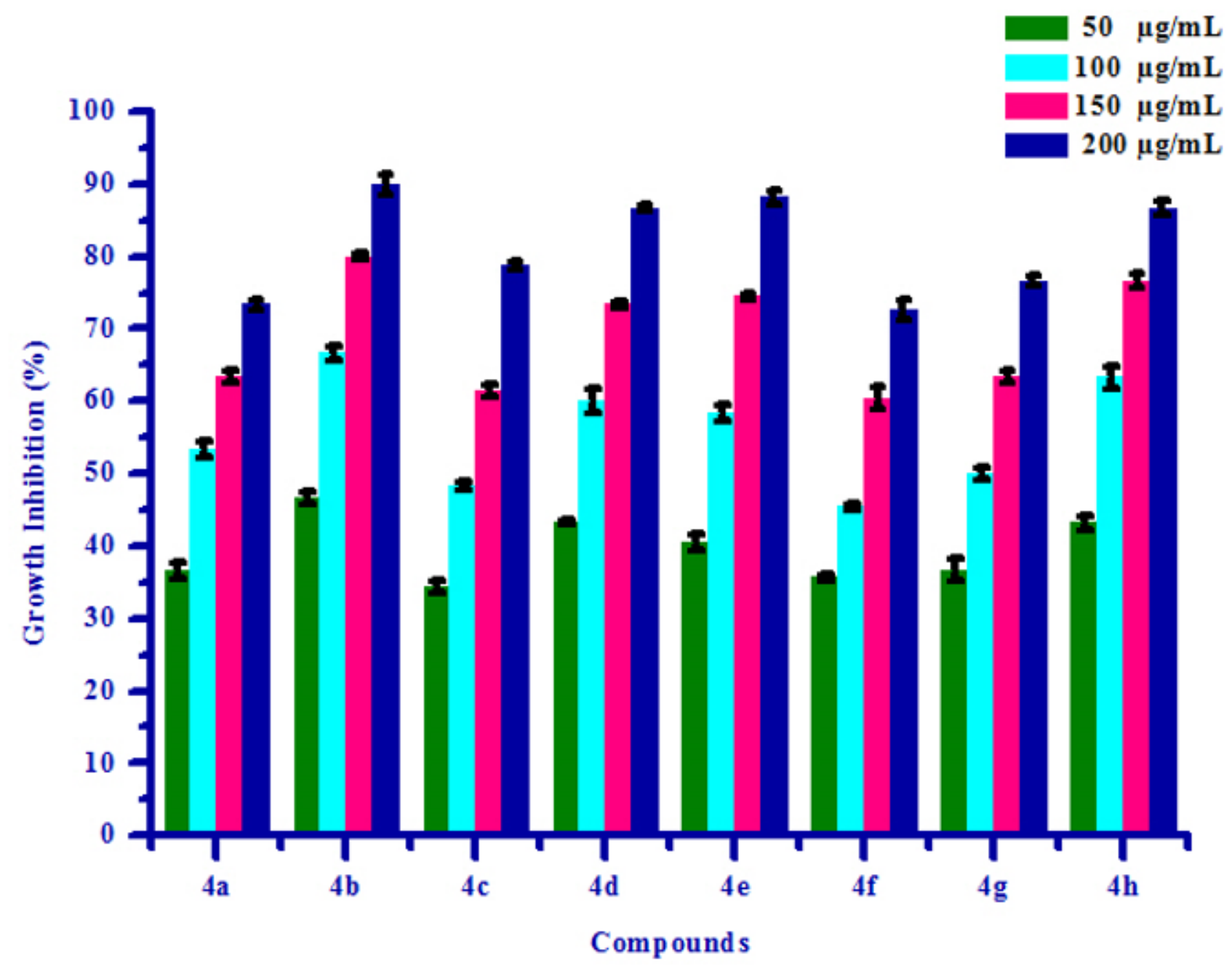

Figure 3

Herbicidal activity of substituted isoxazoles (4a-4h) against Raphanus sativus L. (root) 


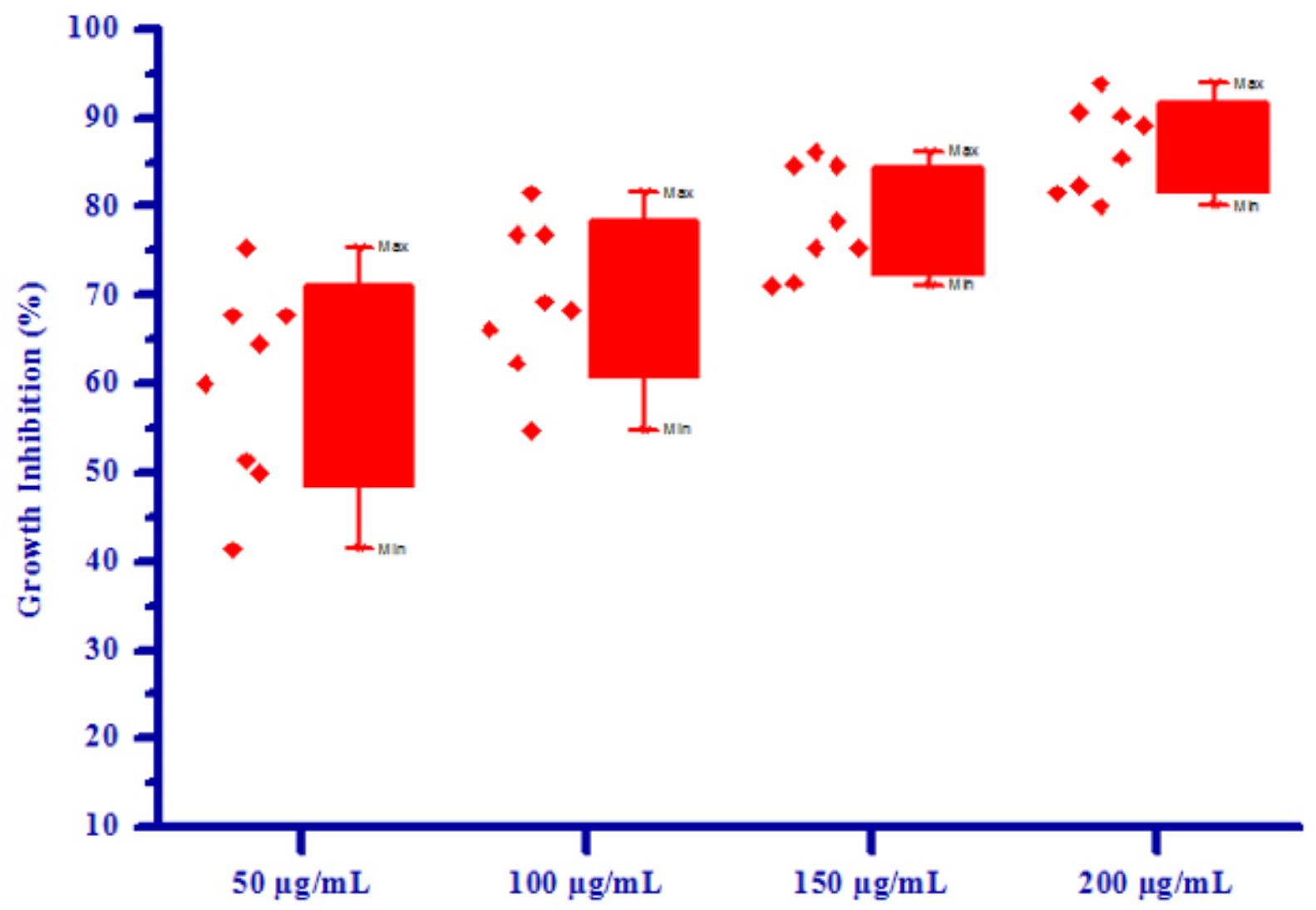

Figure 4

Box plot of substituted isoxazoles (4a-4h) against Raphanus sativus L. (shoot) 


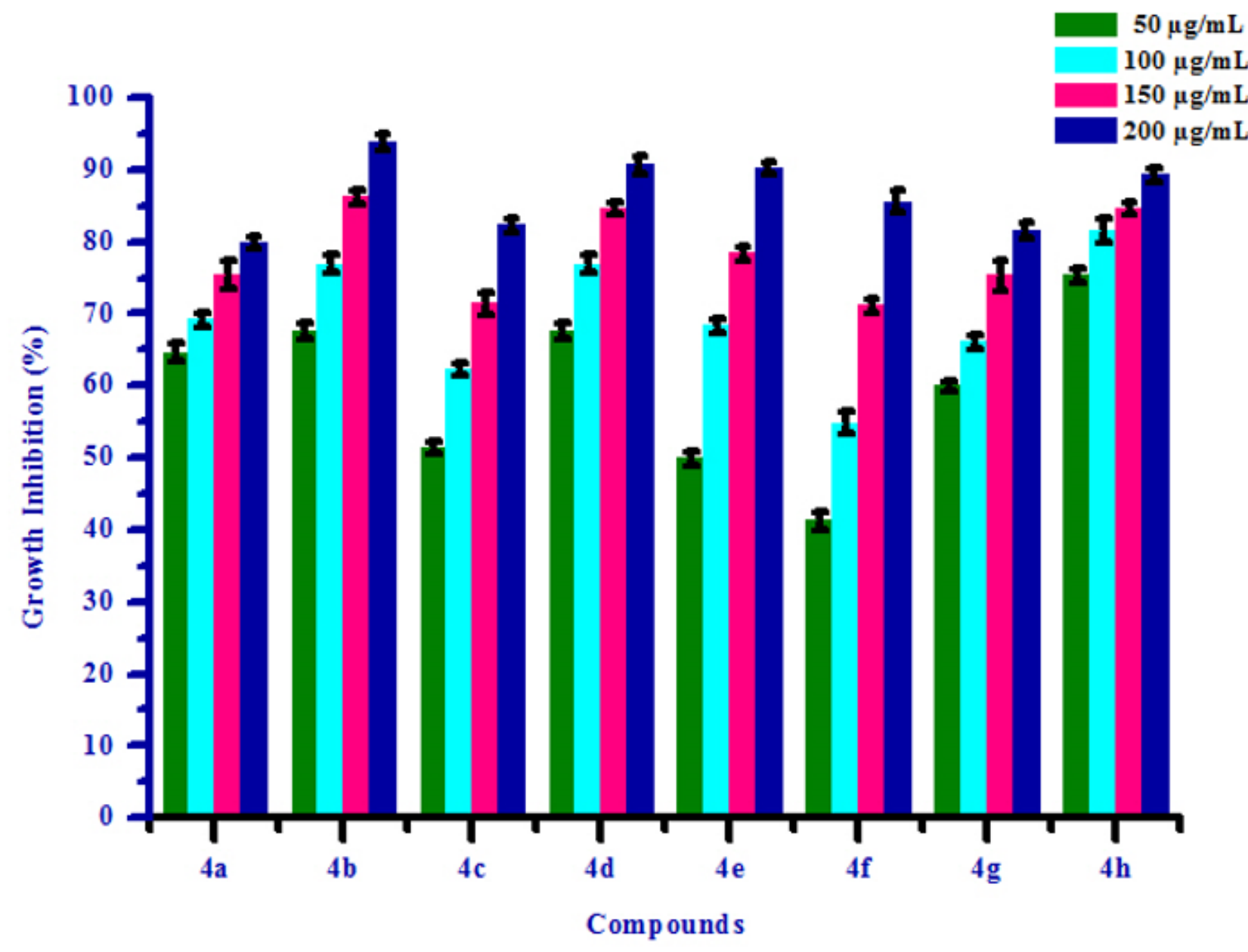

Figure 5

Herbicidal activity of substituted isoxazoles (4a-4h) against Raphanus sativus L. (shoot) 


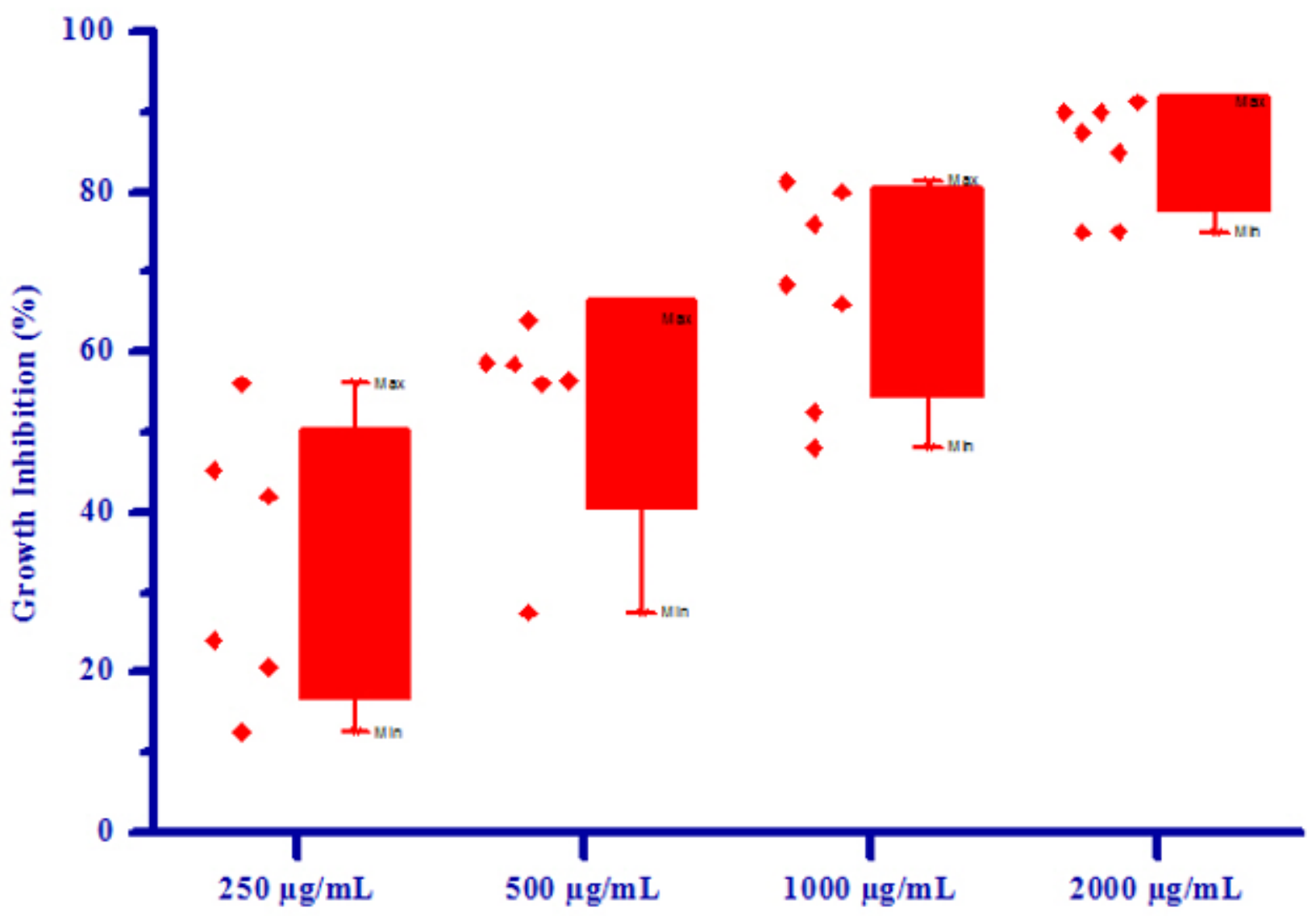

Figure 6

Box plot of substituted isoxazoles (4a-4g) against Rhizoctonia solani 


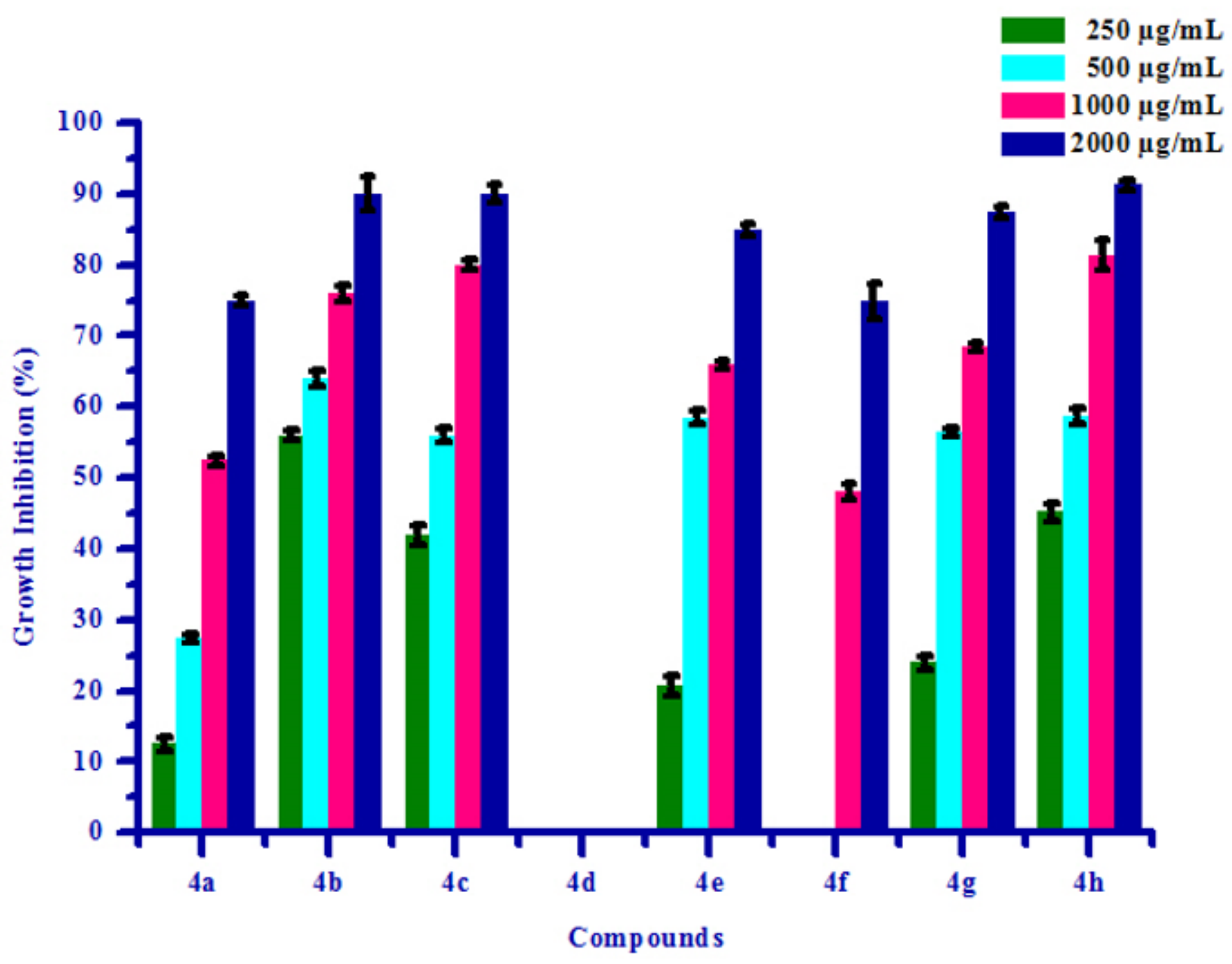

Figure 7

Antifungal activity of substituted isoxazoles (4a-4h) against Rhizoctonia solani 


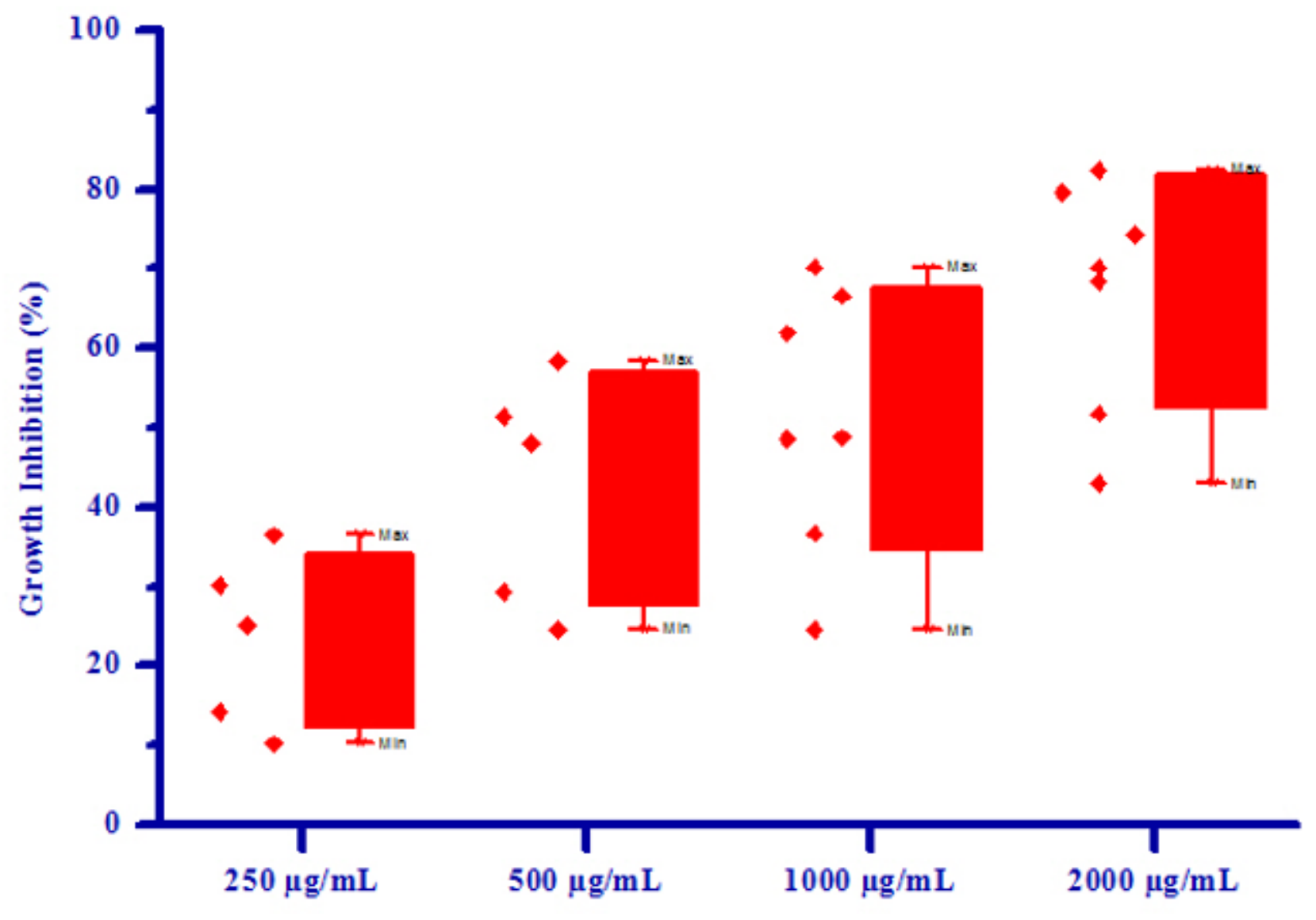

Figure 8

Box plot of substituted isoxazoles (4a-4h) against Colletotrichum gloeosporioides 


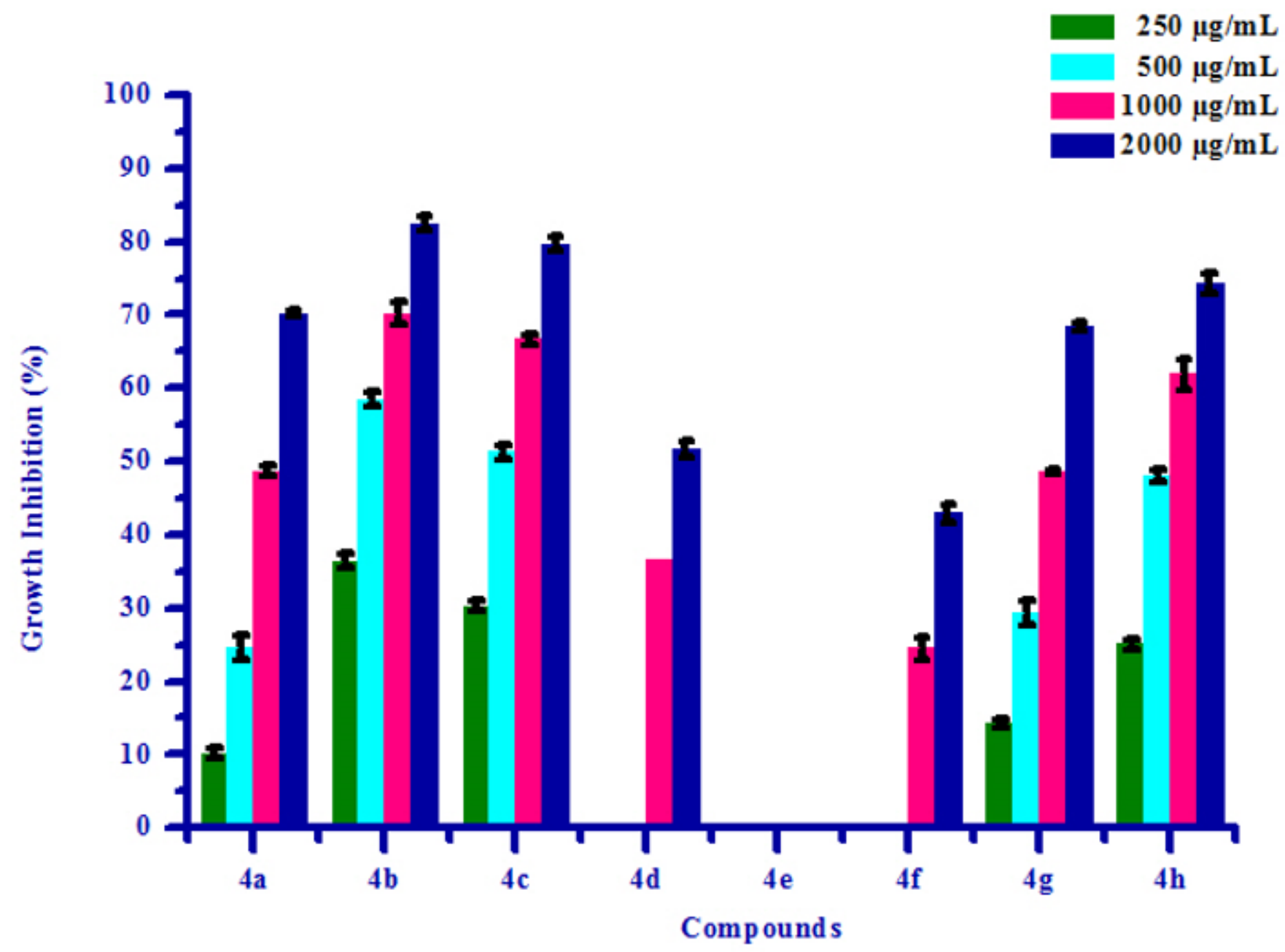

Figure 9

Antifungal activity of substituted isoxazoles (4a-4h) against Colletotrichum gloeosporioides 


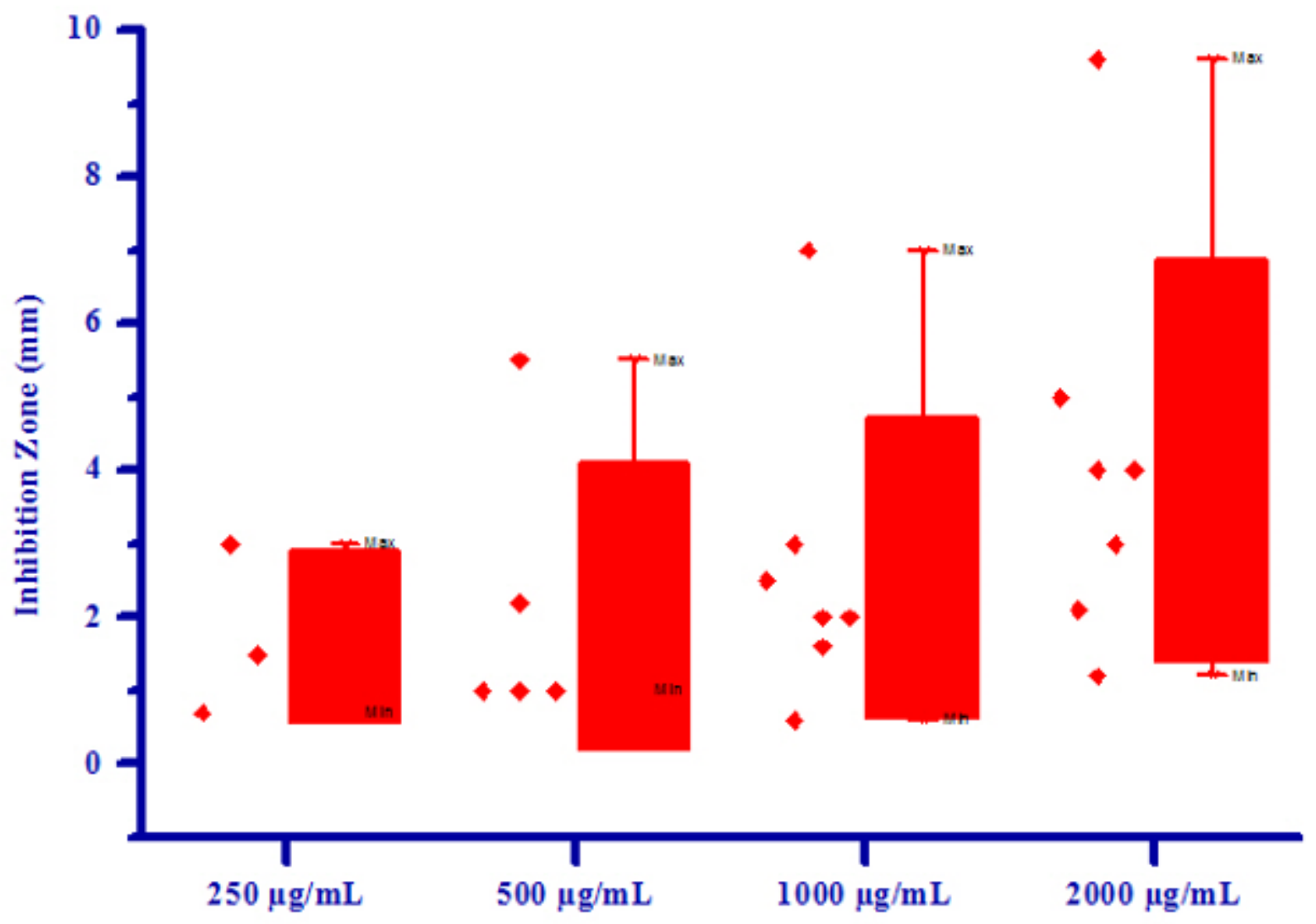

Figure 10

Box plot of substituted isoxazoles (4a-4h) against Erwinia carotovora 


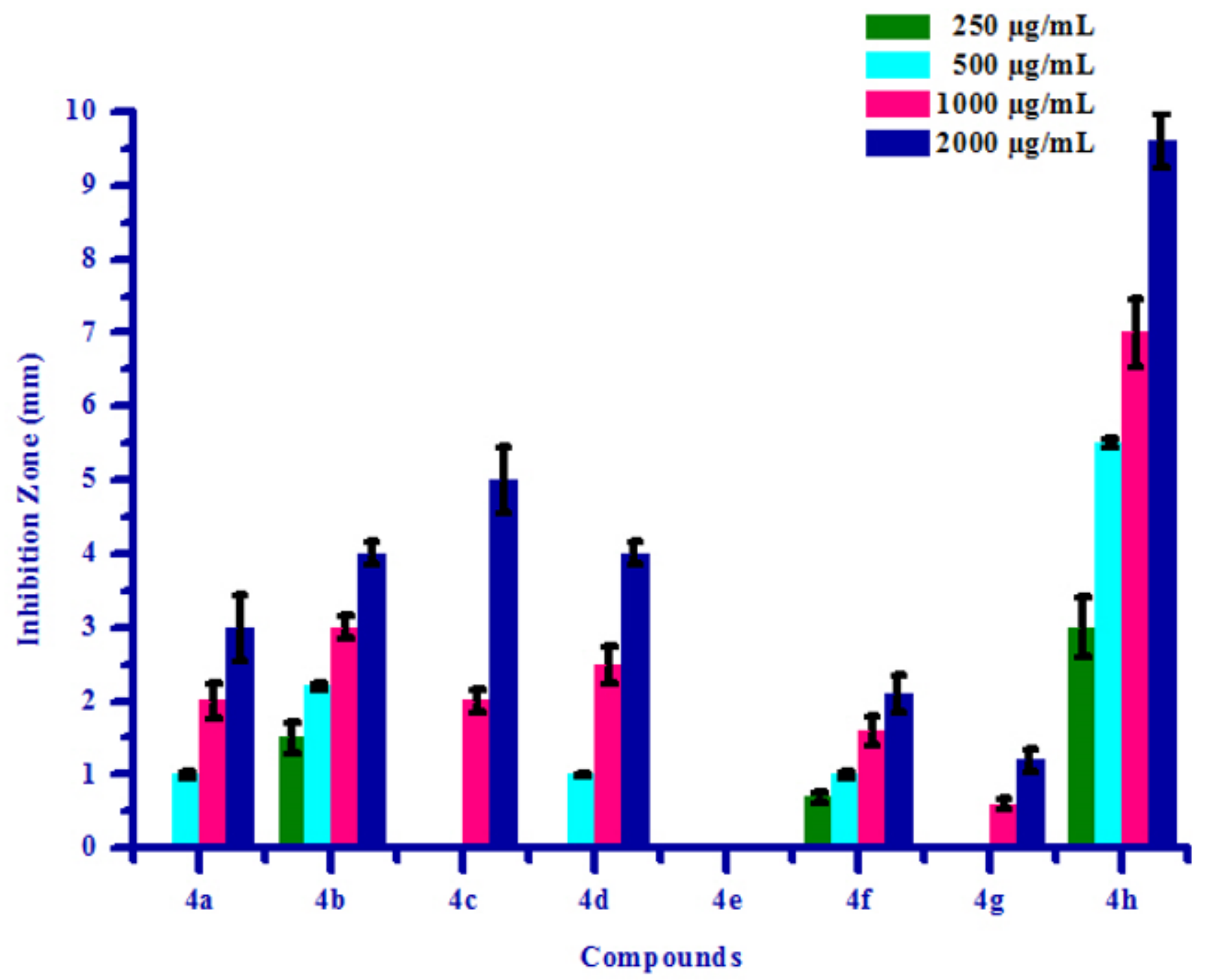

Figure 11

Antibacterial activity of substituted isoxazoles (4a-4h) against Erwina carotovora 


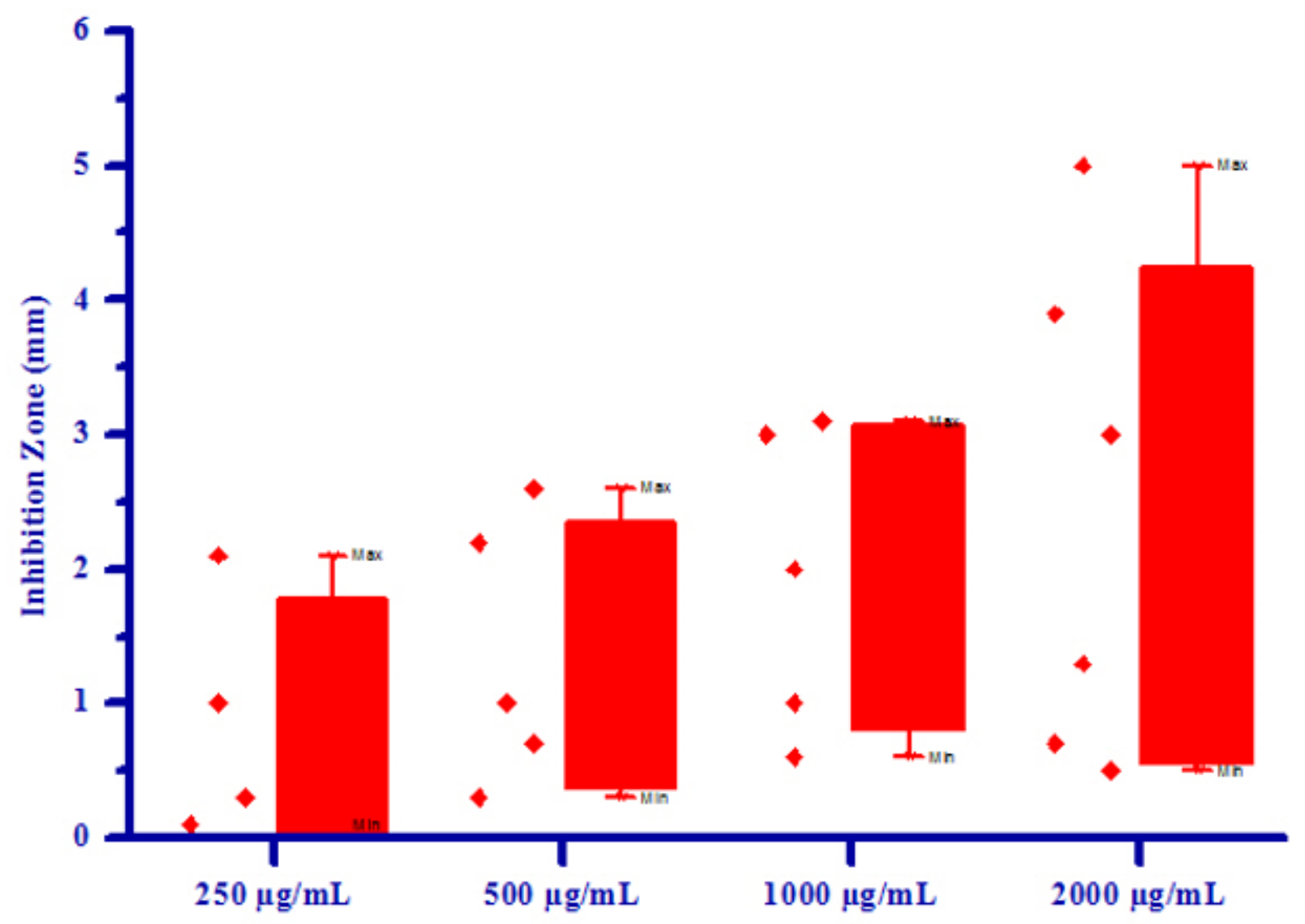

Figure 12

Box plot of substituted isoxazoles (4a-4h) against Xanthomonas citri 


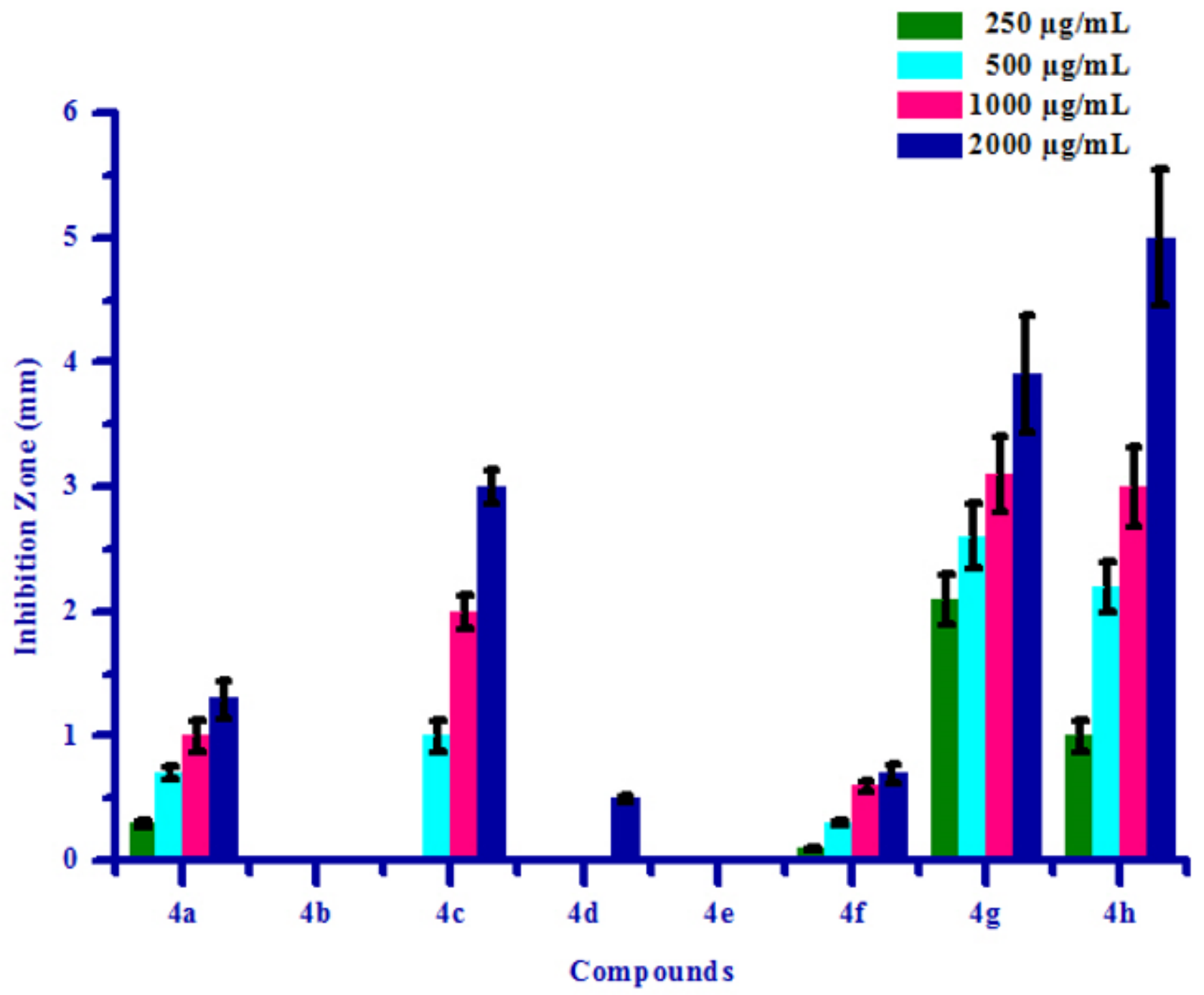

Figure 13

Antibacterial activity of substituted isoxazoles (4a-4h) against Xanthomonas citri

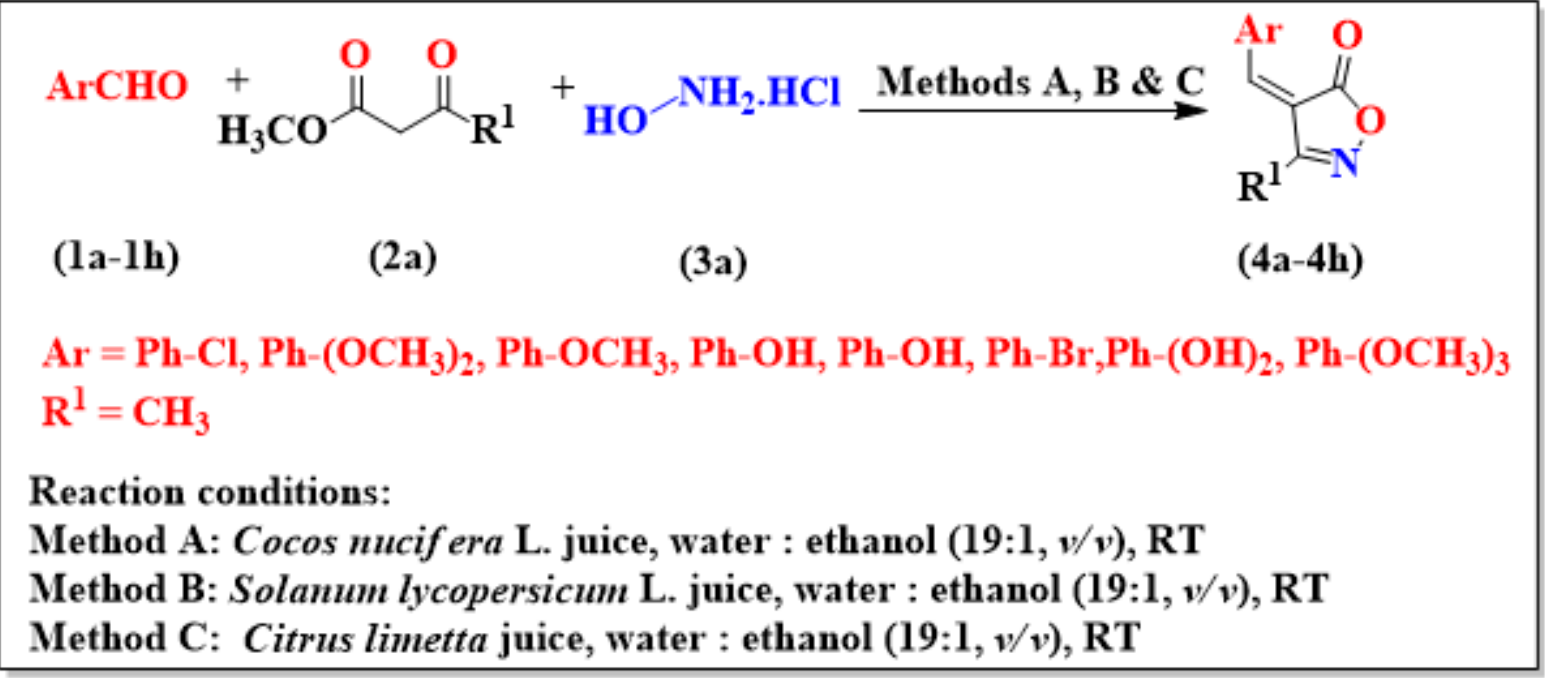

Figure 14 
Scheme 1: Synthesis of substituted isoxazole derivatives (4a-4h)

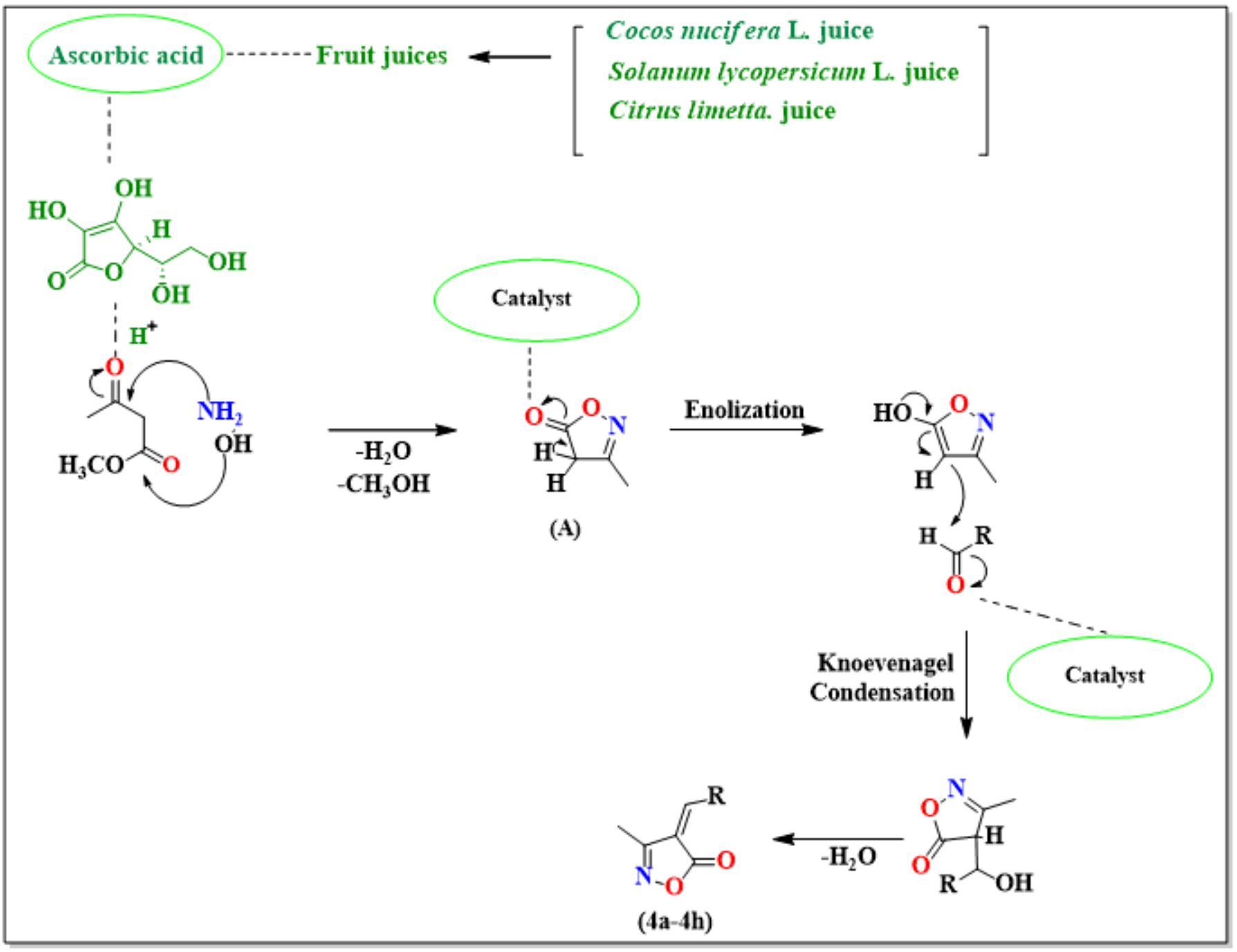

Figure 15

Scheme 2: The possible mechanism for synthesis of substituted isoxazoles (4a-4h)

\section{Supplementary Files}

This is a list of supplementary files associated with this preprint. Click to download.

- floatimage1.png 